\title{
1 The Contribution of Fruit and Vegetable Consumption to Human Health
}

\author{
Elhadi M. Yahia
}

\section{Introduction}

Increasing incidences of some chronic diseases, including cancer and cardiovascular disease, especially in industrial countries, have raised awareness regarding the importance of diet (Erbersdobler 2003). It is estimated that one-third of the cancer cases and up to half of cardiovascular disease cases are thought to be diet related (Goldberg 1994). Numerous epidemiological studies have shown an inverse association between fruit and vegetable consumption and chronic diseases, including different types of cancer and cardiovascular disease (Hirayama 1990; Block and others 1992; Howe and others 1992; Steinmetz and Potter 1991, 1996; World Cancer Research Fund 1997; Joshipura and others 2001; Bazzano and others 2002; Kris-Etherton and others 2002). These studies have shown mounting evidence that people who avoid fruit and vegetables completely, or who consume very little, are indeed at increased risk of these diseases. Therefore, interest in the health benefits of fruit and vegetable consumption is increasing, and the interest in understanding the type, number, and mode of action of the different components in fruits and vegetables that confer health benefits is also increasing.

Fruits and vegetables have historically been considered rich sources of some essential dietary micronutrients and fibers, and more recently they have been recognized as important sources for a wide array of phytochemicals that individually, or in combination, may benefit health (Stavric 1994; Rechkemmer 2001). Therefore, some people have conferred on fruits and vegetables the status of "functional foods." There are many biologically plausible reasons for this potentially protective association, including the fact that many of the phytochemicals act as antioxidants.

Phytochemicals present in fruits and vegetables are very diverse, such as ascorbic acid, carotenoids, and phenolic compounds (Liu 2004; Percival and others 2006; Syngletary and others 2005; Yahia and others 2001a, 2001b). Plant polyphenols are ubiquitous in the diet, with rich sources being tea, wine, fruits, and vegetables; they demonstrate considerable antioxidative activity in vitro, which can have important implications for health (Duthie and others 2000).

Naturally occurring compounds such as phytochemicals, which possess anticarcinogenic and other beneficial properties, are referred to as chemopreventers. One of the predominant mechanisms of their protective action is due to their antioxidant activity and the capacity to scavenge free radicals. Among the most investigated chemopreventers are some vitamins, plant polyphenols, and pigments such as carotenoids, chlorophylls, flavonoids, and betalains. Resolution of the potential protective roles of 


\section{Fruit and Vegetable Phytochemicals}

specific antioxidants and other constituents of fruits and vegetables deserves major attention.

Evidence indicates that for the effect of fruit and vegetable consumption on health, the whole may be more than the sum of the parts; individual components appear to act synergistically where the influence of at least some of these is additive.

Consumption of a diet high in fruits and vegetables increases antioxidant concentration in blood and body tissues and potentially protects against oxidative damage to cells and tissues. Olmedilla and others (2001) described blood concentration of carotenoids, tocopherols, ascorbic acid, and retinol in well-defined groups of healthy nonsmokers, aged 25-45 years; the study included 175 men and 174 women from five European countries (France, Northern Ireland, Republic of Ireland, the Netherlands, and Spain). Analysis was centralized and performed within 18 months. Within-gender, vitamin $\mathrm{C}$ showed no significant differences between countries. Females in France, Republic of Ireland, and Spain had significantly higher plasma vitamin C concentration than their male counterparts. Serum retinol and $\alpha$-tocopherol levels were similar, but $\gamma$-tocopherol showed great variability, being lowest in Spain and France and highest in the Netherlands. The ratio of provitamin A to non-provitamin A carotenoids was similar among countries, whereas the ratio of xanthophylls (lutein, zeaxanthin, and $\beta$-cryptoxanthin) to carotenes ( $\alpha$-carotene, $\beta$-carotene, and lycopene) was double in southern areas (Spain) compared to northern areas (Northern Ireland and Republic of Ireland). Serum concentration of lutein and zeaxanthin were highest in France and Spain and $\beta$-cryptoxanthin was highest in Spain and the Netherlands. trans-Lycopene tended to be highest in Irish males and lowest in Spanish males, whereas $\alpha$-carotene and $\beta$-carotene were higher in the French volunteers. Because of the study design, concentration of carotenoids and vitamins $\mathrm{A}, \mathrm{C}$, and $\mathrm{E}$ represent physiological ranges achievable by dietary means and may be considered as "reference values" in serum of healthy, nonsmoking middle-aged subjects from the five European countries. Results suggest that lutein (and zeaxanthin), $\beta$-cryptoxanthin, total xanthophylls, $\gamma$-tocopherol, and the ratio of $\beta$-tocopherol to $\gamma$-tocopherol may be important markers related to the healthy or protective effects of a Mediterranean-like diet.

The epidemiological evidence indicates that avoidance of smoking, increased consumption of fruits and vegetables, and control of infections can have a major effect on reducing rates of several chronic diseases including cardiovascular disease and different types of cancer (Ames and others 1995; Graham and Mettlin 1981; Giovannucci 1999; Liu 2004; Syngletary and others 2005; Percival and others 2006). It is argued that increasing intake of 400 to $800 \mathrm{~g} /$ day of fruits and vegetables is a public health strategy of considerable importance for individuals and communities worldwide. For this reason the World Health Organization (WHO) recommends a daily intake of more than $400 \mathrm{~g}$ per person daily, and health authorities worldwide promote high consumption of fruits and vegetables. Many of the putative chemoprotective phytochemicals in fruits and vegetables are colored (due to various pigments). The guidelines are based on selecting one daily serving of fruits and vegetables from each of seven color classes (red, yellow-green, red-purple, orange, orange-yellow, green, white-green) so that a variety of phytochemicals is consumed. A study by Johnston and others (2000) during 1994-1996, a "continuing survey of food intakes by individuals," was used to examine the types of fruits and vegetables consumed in the US. The sample 
populations consisted of 4,806 men and women (25-75 years old) who completed two nonconsecutive 24-hr recalls, consumed 3.6-2.3 servings of vegetables and $1.6 \pm 2.0$ servings of fruit daily. Iceberg lettuce, tomatoes, French fried potatoes, bananas, and orange juice were the most commonly consumed fruits and vegetables, accounting for nearly $30 \%$ of all fruits and vegetables consumed. The most popular items, lettuce and tomatoes, were consumed by $39-42 \%$ of the sample population during the reporting period. Fewer respondents (16-24\%) consumed French fried potatoes, bananas, or orange juice. Only $3 \%$ of the sample consumed broccoli during the reporting period. White potato consumption averaged 1.1 servings daily, with French fried potatoes representing 0.4 serving. Tomato product consumption averaged 0.5 serving daily, dark green vegetable consumption averaged 0.2 serving daily, and citrus, berries, or melon consumption amounted to nearly 0.8 serving daily. These data have indicated that people in the US are consuming more fruits and vegetables compared to previous years but that dark green and cruciferous vegetable intake is low. Many studies suggest that consumption of fruit and vegetables is still low in many countries (Naska and others 2000; Agudo and others 2002; USDA 2002; Blanck and others 2008), and efforts are still needed to increase it. This chapter will highlight the potential health benefits of fruit and vegetable consumption on several diseases, as well as the nutritional and health importance of some fruits and vegetables.

\section{Effect of Consumption of Fruit and Vegetables on Some Diseases}

\section{Cancer}

Epidemiological evidence of cancer-protective effects of fruits and vegetables, as well as the basic mechanisms by which phytochemicals in fruits and vegetables can protect against cancer development, has been previously surveyed by Wargovich (2000). Sometimes it was difficult to associate total fruit and vegetable consumption and cancer prevention, but it could be associated with some specific families or types of fruits and vegetables (Steinmetz and Potter 1996; Voorips and others 2000). For example, a high consumption of tomato or tomato-based products is consistently associated with lower risk of different cancer types as shown by meta-analysis, with the highest evidence found for lung, prostate, and stomach cancer (Giovannucci 1999). The metabolism of chemical carcinogens has been shown to be influenced by dietary constituents (Wattenberg 1975). Naturally occurring inducers of increased activity of the microsomal mixed-function oxidase system are present in plants; cruciferous vegetables are particularly potent in this regard. From Brussels sprouts, cabbage, and cauliflower, three indoles with inducing activity have been identified: indole-3-acetonitrile, indole3-carbinol, and 3,3'-diindolylmethane. A second type of dietary constituent that affects the microsomal mixed-function oxidase system is added phenolic antioxidants, butylated hydroxyanisole (BHA), and butylated hydroxytoluene. The feeding of BHA has resulted in microsomal changes in the liver. Spectral characteristics of cytochrome P450 were changed, and the aryl hydrocarbon hydroxylase system of these microsomes demonstrated increased sensitivity to inhibition by $\alpha$-naphthoflavone. A decrease in the binding of metabolites of benzo[a]pyrene to DNA was noted upon incubation of these microsomes with benzo[ $[a]$ pyrene. BHA and butylated hydroxytoluene exert a protective effect against chemical carcinogens. Therefore, it seems that the constituents of 
the diet could be of consequence in the neoplastic response to exposure to carcinogens in the environment.

Several in vitro studies have shown that phenolic compounds in fruits and vegetables have antiproliferative effect in different cancer cell lines (Eberhardt and others 2000; Chu and others 2002; Sun and others 2002; Liu and others 2005; Mertens-Talcott and others 2005; Percival and others 2006).

Quercetin, a flavonoid found in many fruits and vegetables, has been shown to affect the metastatic potential of mouse tumor cells (Suzuki and others 1991). Mutagenicity of quercetin was examined by means of DNA fingerprint analysis using the Pc-1 probe that efficiently detects mutations due to recombination. Treatment of BMT-11 and FM3A tumor cells with quercetin resulted in gain and loss of bands in the fingerprints in both cell lines. The frequencies of the clones having undergone mutation were $3 / 11$ and 6/26, respectively. This suggests that quercetin is mutagenic and induces recombination, and the results seem to provide a molecular basis for the phenotypic variations of BMT-11 tumor cells induced by quercetin. It is important to mention, however, that although in vitro quercetin has consistently tested positive for mutagenic activity in prokaryotic and eukaryotic cells, in vivo experiments have not confirmed these findings, supporting the toxicological safety of quercetin (Harwood and others 2007). Other flavonoids also show mutagenic activity (Takahashi and others 1979).

Chlorophyllin (CHL), a food-grade derivative of the ubiquitous fruit and vegetable pigment chlorophyll, has been shown to be a potent, dose-responsive inhibitor of aflatoxin $\mathrm{B}_{1}$ DNA adduction and hepatocarcinogenesis in the rainbow trout model when fed with carcinogen (Breinholt and others 1995). Chlorophyllins are derivatives of chlorophyll in which the central magnesium atom is replaced by other metals, such as cobalt, copper, or iron. The relative efficacy of chlorophyll and chlorophyllin has been shown to modify the genotoxic effects of various known toxicants (Sarkar and others 1994). CHL neither promoted nor suppressed carcinogenesis with chronic postinitiation feeding. By molecular dosimetry analysis, reduced aflatoxin $\mathrm{B}_{1}$-DNA adduction accounted quantitatively for reduced tumor response up to $2000 \mathrm{ppm}$ dietary CHL, but an additional protective mechanism was operative at $4000 \mathrm{ppm}$ CHL. The finding of potent inhibition (up to 77\%) at CHL levels well within the chlorophyll content of some green fruits and vegetables may have important implications in intervention and dietary management of human cancer risks.

Monoterpenes are natural plant products found in the essential oils of many commonly consumed fruits and vegetables and have been widely used as flavor and fragrance additives in food and beverages. Monoterpenes have been shown to possess antitumorigenic activities (Kelloff and others 1996). Limonene, the simplest monocyclic monoterpene, which is found in some citrus fruits, and perrillyl alcohol, a hydroxylated limonene analog, have demonstrated chemopreventive and chemotherapeutic activity against mammary, skin, lung, pancreas, and colon tumors in rodent models (Crowell and Gould 1994; Wattenburg and Coccia 1991; Stark and others 1995).

Experimental studies (Sugie and others 1993; Dashwood and others 1989; Tanaka and others 1990) have shown that indoles and isothiocyanates (found in Brassica vegetables) given to animals after a carcinogen insult reduced tumor incidence and multiplicity at a number of sites including the liver, mammary gland, and colon. A possible inhibitory activity of isothiocyanates and indoles against tumorigenesis 
apparently stems from their ability to influence Phase I and Phase II biotransformation enzyme activities (Zhang and Talalay 1994; Boone and others 1990; McDannell and McLean 1988). Sulforaphane, which is present in broccoli, is a potent inducer of the Phase II detoxification enzymes quinine reductase and glutathione transferase and an inhibitor of the carcinogen-activating cytochrome P450 2E1 (Zhang and others 1992; Barcelo and others 1996).

Numerous studies (Rungapamestry and others 2007) have indicated that the hydrolytic products of at least three glucosinolates, 4-methylsulfinylbutyl (glucoraphanin), 2-phenylethyl (gluconasturtiin), and 3-indolylmethyl (glucobrassicin), have anticarcinogenic activity. Indole-3-carbinol, a metabolite of glucobrassicin, has shown inhibitory effects in studies of human breast and ovarian cancers. $S$-Methylcysteine sulfoxide and its metabolite methylmethane thiosulfinate were shown to inhibit chemically induced genotoxicity in mice. Thus, the cancer chemopreventive effects of Brassica vegetables that have been shown in human and animal studies may be due to the presence of both types of sulfur-containing phytochemicals (i.e., certain glucosinolates and $S$-methylcysteine sulfoxide).

\section{Stomach}

Reports on an inverse relationship between the consumption of fresh vegetables and human gastrointestinal cancer have been followed by screening for the protective activity of a large number of plant extracts, including leafy vegetables (Botterweck and others 1998; Larsson and others 2006).

Protection for all sites of digestive-tract cancers (oral cavity and pharynx, esophagus, stomach, colon, rectum) was associated with an increased intake of tomato-based foods and an increased supply of lycopene (Franceschi and others 1994). People who ate at least one serving of tomato-based product per day had 50\% less chance of developing digestive tract cancer than those who did not eat tomatoes (Franceschi and others 1994). The intake of lycopene has also been associated with a reduced risk of cancers of sites other than the digestive tract, such as the pancreas and the bladder (Gerster 1997). Older subjects who regularly ate tomatoes were found to be less likely to develop all forms of cancer (Colditz and others 1985). A significant trend in risk reduction of gastric cancers by high tomato consumption was also observed in a study that estimated dietary intake in low-risk versus high-risk areas in Italy (Buiatti and others 1990). A similar regional impact on stomach cancer was also observed in Japan (Tsugani and others 1992), where out of several micronutrients including vitamins A, C, and $\mathrm{D}$ and $\beta$-carotene, only lycopene was strongly inversely associated with stomach cancer. Franceschi and others (1994) have shown a consistent pattern of protection for many sites of digestive tract cancer associated with an increased intake of fresh tomatoes.

Habitual consumption of garlic has been reported to correlate with a reduction in gastric nitrite content and reduction in gastric cancer mortality (Mei and others 1982; You and others 1989). Allium compounds present in garlic have been reported to inhibit the synthesis of $N$-nitroso compounds (Mei and others 1989). In a human study, $5 \mathrm{~g}$ of fresh garlic consumption has shown to markedly suppress urinary excretion of $\mathrm{N}$-nitrosoproline in individuals given supplemental nitrate and proline (Mei and others 1989). In addition, two ecological studies (World Cancer Research Fund Food 1997) 
showed that in areas where garlic or onion production is very high, mortality rates from stomach cancer are very low.

\section{Colon}

Consumption of fruits and vegetables, and the associated vitamin $\mathrm{C}$, carotene, and fiber, has been reported to reduce risk of colon cancer (Ziegler and others 1981). Since plant sterols are plentiful in vegetarian diets, the effect of $\beta$-sitosterol on colon tumor formation in rats treated with the carcinogen $N$-methyl- $N$-nitrosourea was studied by Raicht and others (1980). They have demonstrated that $\beta$-sitosterol nullified in part the effect of this direct-acting carcinogen on the colon. They suggest that plant sterols may have a protective dietary action to retard colon tumor formation, and therefore the beneficial effects of vegetarian diets may be enhanced because of the presence of these compounds.

An increased risk of colon cancer has been associated with decreases in the frequency with which vegetables were eaten in a study of 214 females with cancer of the colon, and 182 females with cancer of the rectum yielded similar results (Graham and others 1978). The decrease in risk was found to be associated with frequent ingestion of vegetables, especially cabbage, Brussels sprouts, and broccoli, and it is consistent with the decreased numbers of tumors observed in animals challenged with carcinogens and fed compounds found in these same vegetables.

Associations between fruit, vegetable, and dietary fiber consumption and colorectal cancer risk were investigated in a population that consumes relatively low amounts of fruit and vegetables and high amounts of cereals (Terry and others 2001). Data were examined from a food-frequency questionnaire used in a population-based prospective mammography screening study of women in central Sweden. Women with a diagnosis of colorectal cancer were identified by linkage to regional cancer registries, and Cox proportional hazards models were used to estimate relative risks; all statistical tests were two-sided. During an average 9.6 years of follow-up of 61,463 women, 460 incident cases of colorectal cancer were observed. In the entire studied population, total fruit and vegetable consumption was inversely associated with colorectal cancer risk, but subanalyses showed that this association was largely due to fruit consumption. The association was stronger and the dose-response effect was more evident among individuals who consumed the lowest amounts of fruit and vegetables; individuals who consumed less than 1.5 servings of fruit and vegetables/day had a higher relative risk of developing colorectal cancer compared with individuals who consumed greater than 2.5 servings.

Diets containing citrus fiber have been reported to reduce the risk of intestinal cancer. The effect of dietary dehydrated citrus fiber on carcinogenesis of the colon and small intestine was studied in male F344 rats by Reddy and others (1981). Weanling rats were fed semipurified diets containing 5\% fat and 15\% citrus fiber; at 7 weeks of age, all animals, except vehicle-treated controls, received weekly injections of $8 \mathrm{mg}$ azoxymethane (AOM)/kg body weight for 10 weeks, and the AOM- or vehicle-treated groups were necropsied 20 weeks after the last injection of AOM. The animals fed the citrus fiber diet and treated with AOM had a lower incidence (number of animals with tumors) and multiplicity (number of tumors/tumor-bearing animal) of colon tumors and tumors of the small intestine than did those fed the control diet and treated with 
AOM. The number of adenomas but not the number of adenocarcinomas was reduced in rats fed on the citrus pulp diet.

The effect of a diet containing 10-40\% lyophilized cabbage or broccoli as cruciferous vegetable or 10-40\% lyophilized potato as noncruciferous vegetable fed for 14 days on the colon mucosal glutathione (GSH) level was studied in male rats (Chen and others 1995). The GSH levels of the duodenum mucosa and the liver were also measured. Cabbage and broccoli enhanced the colon and duodenum mucosal GSH levels in a dose-related manner, but potato had no effect. All three vegetables had no effect on the liver GSH level. The effect of GSH on colon tumorigenesis induced by 1,2-dimethylhydrazine (DMH) was also examined in rats. Male Sprague-Dawley rats were injected weekly with DMH (20 mg/kg body wt) for 20 weeks (Chen and others 1995). DMH lowered the colon mucosal GSH level. GSH (100 mg/day/rat) dissolved in the drinking water and given to rats during and after DMH injections had little or no effect on tumor incidence and total number of colon tumors. Tumors were larger in rats that received GSH than in those that received water. Therefore, it seems likely that the colon mucosal GSH level can be enhanced by feeding rats a diet high in cabbage or broccoli and that GSH added to the drinking water did not affect DMH-induced colon tumorigenesis under the experimental conditions used.

Steinmetz and others (1994) have shown that risk of cancer in the distal colon was $50 \%$ lower in women with the highest consumption of garlic than in women who did not consume garlic.

However, some large cohort studies (Michels and others 2000; Voorips and others 2000) showed no appreciable association between fruit and vegetable intake and colon and rectal cancer.

\section{Breast}

A meta-analysis of 26 prospective and retrospective studies (Gandini and others 2000) confirmed the reduction of the risk of breast cancer with enhanced intake of fruit and vegetables, in contrast to a pooled analysis of eight prospective studies that indicated that fruit and vegetable consumption did not significantly reduce the risk of breast cancer (Smith-Warner and others 2001). A Europe-wide prospective EPIC study (European Prospective Investigation into Cancer and Nutrition) with 285,526 women has demonstrated that a daily intake of $370 \mathrm{~g}$ fruit or $246 \mathrm{~g}$ vegetables is not associated with a reduced breast cancer risk (van Gils and others 2005). Shannon and others (2003) reported a protective effect of vegetable and fruit intake at the highest quartile of consumption, suggesting a threshold effect in reducing breast cancer risk. However, reports indicated that $100 \mathrm{~g}$ of fresh apples have an antioxidant activity equivalent to $1700 \mathrm{mg}$ of vitamin $\mathrm{C}$ and that whole apple extracts prevent breast cancer in a rat model in a dose-dependent manner at doses comparable to human consumption of one, three, and six apples a day (Liu and others 2005). Whole apple extracts were reported to effectively inhibit mammary cancer growth in the rat model; thus consumption of apples was suggested as an effective means of cancer protection. Female Sprague-Dawley rats treated with the carcinogen 7,12-dimethylbenz[a] anthracene (DMBA) at 50 days of age developed mammary tumors with $71 \%$ tumor incidence during a 24-week study, but a dose-dependent inhibition of mammary carcinogenesis by whole apple extracts was observed, where application of low, medium, and high doses of whole apple 
extracts, comparable to $3.3,10$, and $20 \mathrm{~g}$ of apples $/ \mathrm{kg}$ of body weight, reduced the tumor incidence by 17, $39(p<0.02)$, and $44 \%(p<0.01)$, respectively; this is comparable to human consumption of one $(200 \mathrm{~g} / 60 \mathrm{~kg})$, three, and six apples per day.

Garcia-Solis and others $(2008,2009)$ studied the antineoplastic properties of some fruits and vegetables using in vivo and in vitro models. The effect of "Ataulfo" mango fruit consumption was studied on chemically induced mammary carcinogenesis and plasma antioxidant capacity (AC) in rats treated with the carcinogen $N$-methyl- $N$ nitrosourea (MNU) (Garcia-Solis and others 2008). Mango was administered in the drinking water $(0.02-0.06 \mathrm{~g} / \mathrm{mL})$ during both short-term and long-term periods to rats, and plasma antioxidant capacity was measured by ferric reducing/antioxidant power and total oxyradical scavenging capacity assays. Rats treated with MNU had no differences in mammary carcinogenesis (incidence, latency, and number of tumors), nor differences in plasma antioxidant capacity. On the other hand, they (Garcia-Solis and others 2009) used a methylthiazolydiphenyltetrazolium bromide assay to screen the antiproliferative activity of aqueous extracts of avocado, black sapote, guava, mango, cactus stems (cooked and raw), papaya, pineapple, four different prickly-pear fruit, grapes, and tomato on the breast cancer cell line MCF-7. Only the papaya extract had a significant antiproliferative effect, and there was no relationship between total phenolic content and $\mathrm{AC}$ with antiproliferative effect. These results suggested that each plant food has a unique combination in quantity and quality of phytochemicals that could determine its biological activity.

Indole-3-carbinol, 3,3'-diindolylmethane, and indole-3-acetonitrile, three indoles occurring in edible cruciferous vegetables, have been studied for their effects on 7,12dimethylbenz $[a]$ anthracene-induced mammary tumor formation in female SpragueDawley rats and on benzo $[a]$ pyrene-induced neoplasia of the forestomach in female ICR/Ha mice (Wattenberg and Loub 1978). When given by oral intubation $20 \mathrm{hr}$ prior to 7,12-dimethylbenz $[a]$ anthracene administration, indole-3-carbinol and 3,3'diindolylmethane had an inhibitory effect on mammary tumor formation, but indole3 -acetonitrile was inactive. Indole-3-carbinol, when added to the diet for 8 days prior to challenge with 7,12-dimethylbenz $[a]$ anthracene, inhibited mammary tumor formation, whereas indole-3-acetonitrile did not. Dietary administration of all three indoles inhibited benzo $[a]$ pyrene-induced neoplasia of the forestomach in ICR/Ha mice.

The consumption of a mixture of phenolic compounds presented in apple or purple grape juice inhibited mammary carcinogenesis in 7,12-dimethylbenzo[a]anthracene (DMBA) treated rats (Liu and others 2005; Jung and others 2006). However, the individual antioxidants of these foods studied in clinical trials, including $\beta$-carotene, vitamin $\mathrm{C}$, and vitamin $\mathrm{E}$, do not appear to have consistent preventive effects comparable to the observed health benefits of diets rich in fruits and vegetables, suggesting that natural phytochemicals in fresh fruits and vegetables could be more effective than a dietary supplement.

Associations between breast cancer and total and specific fruit and vegetable group intakes were examined using standardized exposure definitions (Smith-Warner and others 2001). Data sources were eight prospective studies that had at least 200 incident breast cancer cases, included assessment of usual dietary intake, and had completed a validation study of the diet assessment method or a closely related instrument. 
These researchers studied 7,377 incident invasive breast cancer cases among 351,825 women whose diet was analyzed at baseline. For highest vs. lowest quartiles of intake, weak nonsignificant associations were observed for total fruits, total vegetables, and total fruits and vegetables. There was no apparent additional benefit for the highest and lowest deciles of intake. There were no associations for green leafy vegetables, eight botanical groups, or 17 specific fruits and vegetables. This study concluded that consumption of fruits and vegetables during adulthood is not significantly associated with reduced risk of breast cancer.

Some research has suggested that diets high in mushrooms may modulate aromatase activity and be useful in chemoprevention against breast cancer by reducing the in situ production of estrogen. The white button mushroom (Agaricus bisporus) suppressed aromatase activity dose dependently (Grube and others 2001). Enzyme kinetics demonstrated mixed inhibition, suggesting the presence of multiple inhibitors or more than one inhibitory mechanism. Aromatase activity and cell proliferation were then measured using MCF-7aro, an aromatase-transfected breast cancer cell line. Phytochemicals in the mushroom aqueous extract inhibited aromatase activity and proliferation of MCF-7aro cells.

\section{Prostate}

Some studies have suggested that ingestion of some fruits and vegetables may potentially reduce risk of prostate cancer (Giovannucci and others 2003; Campbell and others 2004; Stram and others 2006). Several epidemiological studies have reported associations between fruit and vegetable intake and reduced risk of prostate cancer, but the findings are inconsistent and data on clinically relevant advanced prostate cancer are limited (Kirsh and others 2007).

A study at the Harvard School of Public Health done on 48,000 men for 4 years reported that men who ate 10 or more servings of tomato products (such as tomatoes, tomato sauce, pizza sauce) per week had up to $34 \%$ less chance to develop prostate cancer (Giovannucci and others 1995). They showed that lycopene intake from tomatobased products is related to a low risk of prostate cancer, but consumption of other carotenoids ( $\beta$-carotene, $\alpha$-carotene, lutein, $\beta$-cryptoxanthin) or retinol was not associated with the risk of prostate cancer.

Activities of various carotenoids present in foods against human prostate cancer cell lines were investigated (Kotake-Nara and others 2001). Effects of 15 carotenoids on the viability of three lines of human prostate cancer cells, PC-3, DU 145, and $\mathrm{LNCaP}$, were evaluated. When cancer cells were cultured in a carotenoid-supplemented medium for $72 \mathrm{hr}$ at $20 \mathrm{mmol} / \mathrm{liter}, 5,6$-monoepoxy carotenoids, namely, neoxanthin from spinach and fucoxanthin from brown algae, significantly reduced cell viability to 10.9 and $14.9 \%$ for PC-3, 15.0 and $5.0 \%$ for DU 145, and nearly zero and $9.8 \%$ for LNCaP, respectively. Acyclic carotenoids such as phytofluene, xi-carotene, and lycopene, all of which are present in tomato, also significantly reduced cell viability. However, phytoene, canthaxanthin, $\beta$-cryptoxanthin, and zeaxanthin did not affect the growth of the prostate cancer cells. DNA fragmentation of nuclei in neoxanthin- and fucoxanthin-treated cells was detected by in situ TdT-mediated dUTP nick end labeling (TUNEL) assay. Neoxanthin and fucoxanthin reduced cell viability through induction of apoptosis. 


\section{Lung}

Increased fruit and vegetable consumption may protect against lung cancer, although epidemiologic findings are inconclusive. Dosil-Díaz and others (2008) analyzed the effect of fruit and vegetable intake on lung cancer risk in a population in northwest Spain, using data from a hospital-based case-control study including 295 histologically confirmed cases and 322 controls. Controls were patients attending the hospital for minor surgery. After adjustment for sex, age, tobacco use, and occupation, the researchers found no protective effect of overall consumption of fruit (odds ratio 1.49, $95 \%$ confidence interval $0.81-2.73$ ), but green leafy vegetables conferred a protective effect (odds ratio $0.50,95 \%$ confidence interval 0.30-0.83).

The association of fruit and vegetable consumption and lung cancer incidence was evaluated by Linseisen and others (2007) using recent data from the European Prospective Investigation into Cancer and Nutrition (EPIC), applying a refined statistical approach (calibration) to account for measurement error potentially introduced by using food frequency questionnaire (FFQ) data. Between 1992 and 2000, detailed information on diet and lifestyle of 478,590 individuals participating in EPIC was collected, and during a median follow-up of 6.4 years, 1,126 lung cancer cases were observed. In the whole study population, fruit consumption was significantly inversely associated with lung cancer risk, whereas no association was found for vegetable consumption. In current smokers, however, lung cancer risk significantly decreased with higher vegetable consumption, and this association became more pronounced after calibration, the hazard ratio (HR) being 0.78 (95\% CI 0.62-0.98) per $100 \mathrm{~g}$ increase in daily vegetable consumption. In comparison, the HR per $100 \mathrm{~g}$ fruit was 0.92 $(0.85-0.99)$ in the entire cohort and $0.90(0.81-0.99)$ in smokers. Cancer incidence decreased with higher consumption of apples and pears (entire cohort) as well as root vegetables (in smokers).

Wright and others (2008) prospectively examined associations between lung cancer risk and intakes of fruit, vegetables, and botanical subgroups in 472,081 participants aged 50-71 years in the National Institutes of Health (NIH)-AARP Diet and Health Study. Diet was assessed at baseline (1995-1996) with a 124-item dietary questionnaire. A total of 6,035 incident lung cancer cases were identified between 1995 and 2003. Total fruit and vegetable intake was unrelated to lung cancer risk in both men and women, but higher consumption of several botanical subgroups, however, was significantly inversely associated with risk only in men. Association between lung cancer risk and fruit and vegetable consumption was also investigated by Feskanich and others (2000) in 77,283 women in a Nurses' Health Study and 47,778 men in a Health Professionals' Follow-up Study. Diet was assessed using a food frequency questionnaire including 15 fruits and 23 vegetables. Relative risk (RR) of lung cancer within each cohort was estimated using logistic regression models; all statistical tests were two-sided. 519 and 274 lung cancer cases were documented among women and men, respectively. Total fruit consumption was associated with a modestly lower risk among women but not among men. RR for highest versus lowest quintile of intake was 0.79 (95\% confidence interval, $\mathrm{CI}=0.59-1.06)$ for women and $1.12(95 \% \mathrm{CI}=$ 0.74-1.69) for men after adjustment for smoking parameters. Total fruit and vegetable consumption was associated with lower risk of lung cancer among men and women 
who had never smoked, but the reduction was not statistically significant $(\mathrm{RR}=0.63$; $95 \% \mathrm{CI}=0.35-1.12$ in the highest tertile). It is suggested that the inverse association among women was confounded by unmeasured smoking characteristics.

Goodman and others concluded in 1992 that some $\beta$-carotene rich fruits such as papaya, sweet potato, mango, and yellow orange showed little influence on survival of lung cancer patients, and the intake of $\beta$-carotene before diagnosis of lung cancer does not affect the progression of the disease. These authors also concluded that a tomato-rich diet (which contributes high lycopene content but only a little $\beta$-carotene) had a strong positive relationship with survival, particularly among women. However, other studies (Le Marchand and others 1989; Steinmetz and others 1993) concluded that lycopene intake was unrelated to lung cancer.

\section{Cardiovascular disease (CVD)}

CVD is the number one cause of death in the United States, and prevention is at the top of the public health agenda (Retelny and others 2008). Evidence shows that reducing the incidence of coronary heart disease with diet is possible (Retelny and others 2008).

Numerous epidemiological studies have demonstrated evidence that diet rich in fruits and vegetables may protect against CVD (Ness and Powles 1997; Law and Morris 1998; Ness and others 1999; Joshipura and others 2001; Bazzano and others 2002). The positive effect has been accomplished by three servings of vegetables and fruits, and the relative risk could be minimized to a great extent by enhancing the vegetable and fruit consumption by up to 10.2 servings per day. A study on 2,682 men in Finland has also indicated that high intake of fruits and vegetables correlates with reduced risk of cardiovascular disease (Rissanen and others 2003). The inverse relationship between vegetable intake and cardiovascular disease was more evident with smokers consuming at least 2.5 servings per day in comparison with less than one serving per day (Liu and others 2001). Legume consumption was significantly and inversely associated with cardiovascular disease, lowering the risk by about $11 \%$ (Bazzano and others 2001).

The Japan Collaborative Cohort Study for Evaluation of Cancer Risk (Nagura and others 2009), with 25,206 men and 34,279 women aged 40-79 years, whose fruit, vegetable, and bean intakes were assessed by questionnaire at baseline in 1988-1990 and followed for 13 years, concluded that intakes of plant-based foods, particularly fruit intake, were associated with reduced mortality from CVD and all causes among Japanese men and women. However, Nakamura and others (2008) assessed the intake of fruits and vegetables in 13,355 men and 15,724 women in Takayama, Gifu, Japan, using a validated FFQ and found that for women, the highest quartile of vegetable intake compared with the lowest was marginally significant and inversely associated with CVD mortality after adjusting for total energy, age, and nondietary and dietary covariates, but in men, CVD death was not associated with fruit or with vegetable intake.

Radhika and others (2008) examined the relationship between fruit and vegetable intake (g/day) and CVD risk factors in urban south Indians. The study population composed of 983 individuals aged at least 20 years selected from the Chennai Urban Rural Epidemiological Study (CURES), a population-based cross-sectional study 
on a representative population of Chennai in southern India, and fruit and vegetable intake (g/day) was measured using a validated semiquantitative FFQ. Linear regression analysis revealed that after adjusting for potential confounders such as age, sex, smoking, alcohol, body mass index (BMI), and total energy intake, the highest quartile of fruit and vegetable intake (g/day) showed a significant inverse association with systolic blood pressure, total cholesterol, and low-density lipoprotein (LDL)cholesterol concentration when compared with the lowest quartile. A higher intake of fruit and vegetables explained $48 \%$ of the protective effect against CVD risk factors.

It has been reported that death attributed to cardiovascular and coronary heart diseases showed strong and consistent reductions with increasing nut/peanut butter consumption (Blomhoff and others 2006). Nuts, including peanuts, have been recognized as having the potential to improve the blood lipid profile, and, in cohort studies, nut consumption has been associated with a reduced risk of coronary heart disease (CHD) (Jenkins and others 2008). Data from the Nurses Health Study indicate that frequent nut consumption is associated with a reduced risk of developing cardiovascular disease. Epidemiologic and clinical trial evidence has demonstrated consistent benefits of nut and peanut consumption on coronary heart disease (CHD) risk and associated risk factors (Kris-Etherton and others 2008). A pooled analysis of four US epidemiologic studies showed that subjects in the highest intake group for nut consumption had an approximately $35 \%$ reduced risk of CHD incidence, and the reduction in total CHD death was due primarily to a decrease in sudden cardiac death. Clinical studies have evaluated the effects of many different nuts and peanuts on lipids, lipoproteins, and various CHD risk factors, including oxidation, inflammation, and vascular reactivity (Kris-Etherton and others 2008). Evidence from these studies consistently shows a beneficial effect on these CHD risk factors. The LDL cholesterol-lowering response of nut and peanut studies is greater than expected on the basis of blood cholesterol-lowering equations that are derived from changes in the fatty acid profile of the diet. Thus, in addition to a favorable fatty acid profile, nuts and peanuts contain other bioactive compounds that explain their multiple cardiovascular benefits. Other macronutrients include plant protein and fiber; micronutrients including potassium, calcium, magnesium, and tocopherols; and phytochemicals such as phytosterols, phenolic compounds, resveratrol, and arginine. Kris-Etherton and others (2008) have indicated that nuts and peanuts are food sources that are a composite of numerous cardioprotective nutrients and if routinely incorporated in a healthy diet, population risk of CHD would therefore be expected to decrease markedly.

Hung and others (2003) evaluated the association of consumption of fruits and vegetables with peripheral arterial disease in a cohort study of 44,059 men initially free of cardiovascular disease and diabetes, reporting no evidence that fruit and vegetable consumption protects against peripheral arterial disease, although a modest benefit cannot be excluded. In the age-adjusted model, men in the highest quintile had a relative risk of 0.55 (95\% confidence interval $=0.38-0.80)$ for overall fruit and vegetable intake, $0.52(0.36-0.77)$ for fruit intake, and $0.54(0.36-0.81)$ for vegetable intake, compared with those in the lowest quintile of intake. However, the associations were greatly weakened after adjustment for smoking and other traditional cardiovascular disease risk factors. 
Pure $\beta$-carotene supplementation (30-50 mg per day) had no depressive effects on cardiovascular disease risk (Hennekens and others 1996; Omenn and others 1996; Lee and others 1999).

Monounsaturated fats in avocados have been shown to reduce blood cholesterol while preserving the level of high-density lipoproteins (Yahia 2009b). An avocadoenriched diet produced a significant reduction in LDL and total cholesterol in patients with high cholesterol levels, whereas diets enriched with soy and sunflower did not change the total cholesterol concentrations (Carranza and others 1997).

Lycopene from tomato fruit was found to prevent the oxidation of LDL cholesterol and to reduce the risk of developing atherosclerosis and coronary heart disease (Agarwal and Rao 1998), and a daily consumption of tomato products providing at least $40 \mathrm{mg}$ of lycopene was reported to be enough to substantially reduce LDL oxidation. Lycopene is recognized as the most efficient singlet oxygen quencher among biological carotenoids (Di Mascio and others 1991, 1989). Lycopene has also been reported to increase gap-junctional communication between cells and to induce the synthesis of connexin-43 (Zhang and others 1992).

\section{Diabetes Mellitus}

The association between the intake of fruit and vegetables and the risk of type 2 diabetes is unclear. Hamer and Chida (2007) have suggested that the consumption of three or more daily servings of fruit or vegetables was not associated with a substantial reduction in the risk of type 2 diabetes, but the intake of antioxidants was associated with a $13 \%$ reduction in risk, mainly attributed to vitamin E. Five cohort studies of fruit and vegetables intake and the risk of diabetes using 167,128 participants and 4,858 incident cases of type 2 diabetes, with a mean follow-up of 13 years, were reviewed by Hamer and Chida (2007). The relative risk of type 2 diabetes for consuming five or more servings of fruit and vegetables daily was 0.96 (95\% CI, 0.79-1.17, $P=0.96), 1.01(0.88-1.15, P=0.88)$ for three or more servings of fruit, and 0.97 $(0.86-1.10, P=0.59)$ for three or more servings of vegetables. Nine cohort studies of antioxidant intake and the risk of diabetes were also identified, incorporating 139,793 participants and 8,813 incident cases of type 2 diabetes, with a mean follow-up of 13 years (Hamer and Chida 2007) indicated that the pooled relative risk was 0.87 $(0.79-0.98, P=0.02)$ for the highest compared with the lowest antioxidant intake. Villegas and others (2008) examined the associations between fruit and vegetable intake and the incidence of type 2 diabetes (T2D) in a population-based prospective study of 64,191 Chinese women with no history of T2D or other chronic diseases at study recruitment and with valid dietary information. Individual vegetable groups were all inversely and significantly associated with the risk of T2D, but there was no association with fruit intake.

Randomized controlled trials of patients with type 2 diabetes have confirmed the beneficial effects of nuts on blood lipids, also seen in nondiabetic subjects, but the trials have not reported improvement in A1c or other glycated proteins (Jenkins and others 2008). Therefore, Jenkins and others (2008) concluded that there is justification to consider the inclusion of nuts in the diets of individuals with diabetes in view of their potential to reduce CHD risk, even though their ability to influence overall glycemic control remains to be established. 
Nettleton and others (2008) characterized dietary patterns and their relation to incident type 2 diabetes in 5,011 participants from the Multi-Ethnic Study of Atherosclerosis (MESA) and found that high intake of whole grains, fruit, nuts/seeds, green leafy vegetables, and low-fat dairy was associated with a $15 \%$ lower diabetes risk.

Bazzano and others (2008) concluded that consumption of green leafy vegetables and fruit was associated with a lower hazard of diabetes, whereas consumption of fruit juices may be associated with an increased hazard among women. A total of 71,346 female nurses aged 38-63 years who were free of cardiovascular disease, cancer, and diabetes in 1984 were followed for 18 years, and dietary information was collected using a semiquantitative FFQ every 4 years (Bazzano and others 2008). During followup, 4,529 cases of diabetes were documented; the cumulative incidence of diabetes was $7.4 \%$, and an increase of three servings/day in total fruit and vegetable consumption was not associated with development of diabetes, whereas the same increase in whole fruit consumption was associated with a lower hazard of diabetes. An increase of 1 serving/day in green leafy vegetable consumption was associated with a modestly lower hazard of diabetes, whereas the same change in fruit juice intake was associated with an increased hazard of diabetes.

Experimental evidence showed that consumption of prickly pear cladodes (nopal) could decrease blood glucose levels (Frati and others 1990a). The intake of broiled Opuntia stems for 10 days improved glucose control in a small group of adults with noninsulin-dependent diabetes mellitus (NIDDM) (Frati and others 1990b, 1983). The rise in serum glucose levels that follows the intake of a sugar load (oral glucose tolerance test) was lower with previous ingestion of Opuntia stems compared to the ingestion of sugar alone (Frati and others 1990a). In patients with NIDDM, the ingestion of some species of nopal (Opuntia streptacantha, O. ficus-indica) in fasting condition is generally followed by a decrease of serum glucose and serum insulin levels (Frati 1992). These positive health effects of Opuntia stems might be associated with dietary fiber, since similar results can be achieved by Plantago psyllium or other sources of dietary fiber (Frati 1992). Ingestion of raw and cooked Opuntia ficus-indica extracts resulted in beneficial effects on total cholesterol, without any secondary effect on glucose and lipoproteins amounts in blood (Medellin and others 1998).

Some flavonoids, such as procyanidins, have antidiabetic properties because they improve altered glucose and oxidative metabolisms of diabetic states (Pinent and others 2004). Extract of grape seed procyanidins (PE) administered orally to streptozotocininduced diabetic rats resulted in an antihyperglycemic effect, which was significantly increased if PE administration was accompanied by a low insulin dose (Pinent and others 2004). The antihyperglycemic effect of PE may be partially due to the insulinomimetic activity of procyanidins on insulin-sensitive cell lines.

\section{Obesity}

Nowadays, obesity is considered a major public health issue, especially in most developed countries, because it is widely spread across population groups and because it contributes to the development of chronic diseases, particularly cardiovascular diseases and diabetes.

Despite the alarming increase in the prevalence of obesity in the world, epidemiologic studies on the relation between fruit and vegetable consumption and weight gain 
(WG) are still insufficient. Vioque and others (2008) explored the associations between fruit and vegetable intake and WG over a 10-year period in an adult Mediterranean population of 206 aged 15-80 years at baseline in 1994, who participated in a nutrition survey in Valencia, Spain. They concluded that dietary patterns associated with a high intake of fruits and vegetables in Mediterranean populations may reduce long-term risk of subsequent WG and obesity among adults.

Svendsen and others (2007) assessed the effect of an increased consumption of vegetables and fruit on body weight, risk factors for CVD and antioxidant defense in obese patients with sleep-related breathing disorders (SRBDs). They concluded that targeted dietary advice to increase the intake of vegetables and fruit among subjects with SRBD contributed to weight reduction and reduced systolic and diastolic blood pressure, but had no effect on antioxidant defense measured by ferric-reducing/antioxidant power (FRAP) assay.

He and others (2004) examined the changes in intake of fruits and vegetables in relation to risk of obesity and weight gain among middle-aged women through a prospective cohort study with 12 years of follow-up, conducted in the Nurses' Health Study with a total of 74,063 female nurses aged 38-63 years, who were free of cardiovascular disease, cancer, and diabetes at baseline in 1984. During the 12-year follow-up, participants tended to gain weight with aging, but those with the largest increase in fruit and vegetable intake had a $24 \%$ lower risk of becoming obese compared with those who had the largest decrease in intake after adjustment for age, physical activity, smoking, total energy intake, and other lifestyle variables. For major weight gain $(\geq 25 \mathrm{~kg}$ ), women with the largest increase in intake of fruits and vegetables had a $28 \%$ lower risk compared to those in the other extreme group.

Bes-Rastrollo and others (2006) assessed the association of fiber intake and fruit and vegetable consumption with the likelihood of weight gain in a Mediterranean (Spain) population with a cross-sectional analysis of 5,094 men and 6,613 women in a multipurpose prospective cohort (Seguimiento Universidad de Navarra Study). There was a significant inverse association between total fruit/vegetable consumption and weight gain, but only among men, and it was more evident among those with a high intake of total fiber; the benefit of total fiber was more evident among those with a high consumption of fruits and vegetables.

de Carvalho and others (2006) evaluated the dietary fiber intake of adolescents in the metropolitan area of Sao Paulo city and the association between low dietary fiber intake and constipation and overweight. The study included 716 adolescents, and evaluation of fiber intake was based on a 24-hr daily intake record and a frequency questionnaire. Adolescents who did not eat beans on more than 4 days per week presented a higher risk of fiber intake below that recommended, and dietary fiber intake below that recommended was associated with a greater risk of overweight in students attending public schooling.

\section{Pulmonary Health}

Several studies have suggested a positive association between fruit and vegetable intake (particularly fruit) and pulmonary function (Walda and others 2002; Watson and others 2002; Celik and Topcu 2006). Fruit and vegetable consumption has been suggested to maintain a healthy pulmonary function in well-adult populations, and improving lung 
function in those with established pulmonary disorders. Phytochemicals, especially of antioxidant potential, have been suggested to be important in protecting lungs from oxidative stress. In a study of 2,917 men in seven European countries, higher fruit intake was found to be consistently associated with lowered mortality from chronic obstructive pulmonary disease (COPD)-related causes and that the trend was statistically significant when age, country of residence, and smoking were considered (Walda and others 2002). This study has shown that vegetables and the antioxidant nutrients vitamins $\mathrm{C}$ and $\beta$-carotene did not correlate with COPD mortality, but vitamin $\mathrm{E}$ intake did appear to be protective when data were adjusted for age, country, and smoking. Fruit intakes of over $121 \mathrm{~g} /$ day and increased vegetable consumption were reported to be associated with significantly reduced COPD (Watson and others 2002; Celik and Topcu 2006).

It has been suggested that reduced antioxidant intake is one critical factor associated with increased susceptibility to asthma (Devereux and Seaton 2005), and therefore fruit and vegetable intake has been suggested to reduce it (Patel and others 2006) by improving ventilatory function and respiratory symptoms (Romieu and others 2006). Fruits and vegetables that were found to be associated with reduced incidence of asthma included green leafy vegetables (intake of $>90 \mathrm{~g} /$ day; $22 \%$ risk reduction), tomato (intake of $>28.2 \mathrm{~g} / \mathrm{day} ; 15 \%$ risk reduction), carrots (intake of $>24.9 \mathrm{~g} / \mathrm{day}$; $19 \%$ risk reduction), and apples (intake of $>31.2 \mathrm{~g} /$ day; $10 \%$ risks reduction). These studies have suggested that high carotenoid content in the food could account for the effect, although results of studies focused on $\beta$-carotene have not been consistent. The consumption of fruit and vegetables was reported to be significantly associated with reduced occurrence of wheezing and shortness of breath in 2,103 boys and 2,001 girls aged 6-7 years from Italy (Farchi and others 2003), and in more than 20,000 children, aged 7-11, from 25 areas in Central and Eastern Europe (Antova and others 2003). Kelly and others (2003) suggested an association between fruit and vegetable intake and improved respiratory function in more than 6,000 healthy adults in Scotland. However, contradicting data have also been reported, such as the study of Lewis and others (2005) reporting no association between asthma prevalence and fruit intake in 11,562 children aged 4-6 years and living in the United Kingdom based on data provided by parents of the study subjects and in 598 Dutch children aged 8-13 years (Tabak and others 2006).

\section{Bone Health}

The loss of bone mass is a global epidemic associated with osteoporosis (Lanham-New 2006). Fruit and vegetable consumption has been suggested to improve bone status (Lanham-New 2006; Bueline and others 2001; Pryne and others 2006). Higher fruit and vegetable intake was associated with improved markers of bone status in males and females ranging between 16 and 83 years old (Pryne and others 2006). Tylavsky and others (2004) showed that fruit and vegetable intake might be important in bone health in white girls aged $8-13$ years. The effect was high with 3 servings/day or more and low with less than 3 servings/day, with 4.0 servings (1.6 fruit/2.4 vegetables) in the high group and 1.7 servings ( 0.6 fruit/1.1 vegetable) in the low group. Girls in the high fruit and vegetable intake group had significantly larger bone area of the whole body and wrist, and higher mineral content for whole body and at the wrist. A study 
of 1,407 premenopausal farm women from five rural districts in Japan has concluded that fruit and vegetable intake is positively correlated with bone health (Okabo and others 2006). In a study conducted with 85 boys and 67 girls, aged 8-20 years, in Saskatchewan, Canada (Vatanparast and others 2005), fruit and vegetable intake was reported to be an important independent predictor of accrued total body bone mineral content in boys but not in girls. In a study with adolescents aged 12 and 15 years in Northern Ireland $(n=1,345), 12$-year-olds consumed the greatest quantity of fruit, and a positive association has been demonstrated between bone density and fruit intake.

Antioxidants in fruits and vegetables including vitamin $C$ and $\beta$-carotene reduce oxidative stress on bone mineral density, in addition to the potential role of some nutrients such as vitamin $\mathrm{C}$ and vitamin $\mathrm{K}$ that can promote bone cell and structural formation (Lanham-New 2006). Many fruits and vegetables are rich in potassium citrate and generate basic metabolites to help buffer acids and thereby may offset the need for bone dissolution and potentially preserve bone. Potassium intake was significantly and linearly associated with markers of bone turnover and femoral bone mineral density (Macdonald and others 2005).

Lin and others (2003) indicated that high potassium, magnesium, and calcium content in addition to antioxidants, phytochemicals, and lower acidity of fruits and vegetables could be important factors for bone health.

In a study with 40 healthy men and women, average age 63.7 years, who were randomized to either an "alkali" diet (meat plus fruits and vegetables) or an "acid" diet (meat plus cereal grains) (Jajoo and others 2006), altering the renal net acid excretion over a period of 60 days affected several biochemical markers of bone turnover and calcium excretion. The acidity of the diet had a significant effect on increasing NTX, a urinary marker of bone breakdown, and increasing the amount of calcium excreted in the urine.

\section{Cataracts and Eye Health}

Oxidative mechanisms have been implicated in the etiology of cataracts in humans, and fruit and vegetables intake has been associated with this problem. A study involving 35,724 healthy professional women over the age of 45 years in the US was conducted to determine the potential association between fruit and vegetable intake and subsequent risk of cataract development over a 10-year follow-up period (Christen and others 2005). Relative risk of developing cataracts during the 10-year study was only slightly reduced in women with the highest intake of fruits and vegetables (10 servings/ day) compared to those with the lowest intake ( 2.6 servings/day). A study of 479 women with an average fruit intake of 2.5 servings/day and average vegetable intake of approximately 4 servings/day also indicated that fruit and vegetable intake did not differ between women with and without nuclear opacities (Moeller and others 2004). The authors concluded that multiple aspects of the diet are more important in reducing the risk of cataracts than emphasizing one particular food group or component over another. In a study with 98 participants, $68 \%$ women, ranging in age between 45 and 73 years, macular pigment optical density (MPOD) was used as a marker, to correlate diet and serum carotenoid levels with the amount of molecular pigment in the retina showing that high ( $\geq 5$ servings/day) intake of fruit and vegetables was associated 
with significantly higher MPOD compared to measurement in subjects with lower $(<3$ servings /day) intake (Burke and others 2005).

\section{Arthritis}

Dietary antioxidants and anti-inflammatory components in food are thought to be important in reducing the risk or improving the course of rheumatoid arthritis (RA), and therefore fruit and vegetable consumption has been associated with reduced risk of RA (Pattison and others 2004b). A study with 29,368 married women from the US, predominately white, average age 61.4 years, lasting 11 years, indicated that total fruit consumption ( $>83$ servings per month) was associated with reduced risk of RA (Cerhan and others 2003). Oranges were the only individual fruit linked to reduce incidence of RA, and $\beta$-cryptoxanthin, a carotenoid found in this fruit, was consistently highly protective. Total vegetable intake was not associated with reduced incidence of RA, but intake of cruciferous vegetables ( $>11$ servings/month), particularly broccoli ( $>3$ servings/month), was associated with a moderate effect on RA. In a study where dietary intake for 73 cases was compared to intake of 146 controls (mean age 60-61 years; 70\% women), lower, but not statistically significant, intake of fruits and vegetables was weakly associated with higher incidence of inflammatory polyarthritis (IP) (Pattison and others 2005). Subjects with the lowest intake $(<55.7 \mathrm{mg} /$ day) of vitamin $\mathrm{C}$ were three times more likely to develop IP than those with the highest intake $(>94.9 \mathrm{mg} / \mathrm{day})$. In a related study to determine the relationship with carotenoid intake, the diets of 88 cases were compared to those of 176 controls (mean age 61 years; $69 \%$ women); intake of vitamin $\mathrm{C}$ and dietary carotenoids, particularly $\beta$-cryptoxanthin and to a lesser extent, zeaxanthin, was found to be significantly correlated with reduced risk of IP (Pattison and others 2005).

\section{Birth Defects}

The effect of folic acid supplementation on reducing the risk of neural tube defects of the brain and spine, including spina bifida and anencephaly, is well documented (Eichholzer and others 2006). Fruits and vegetables are an important source of dietary folate, and their consumption has been associated with increased plasma levels of folate. Plasma folate concentration increased by 13-27\% after short-term feeding experiments with fruits and vegetables (Brevick and others 2005), and red blood cell folate also increased with increasing fruit and vegetable intake (from 1 to 7 servings/day) (Silaste and others 2003).

\section{Diverticulosis}

Diverticulosis, or the presence of several diverticula, affects 50\% or more of the population over the age of 60 years in several countries (Ye and others 2005). Studies have established an association between low-fiber diets and the presence of diverticulosis (Aldoori and Rayan-Harschman 2002). The intake of fruit and vegetable fiber was inversely associated with risk of diverticulosis in a large prospective study of male health professionals, and therefore a high-fiber diet including fruits and vegetables remains an important aspect of therapy for diverticulosis (American Dietetic Association 2002). 


\section{Skin Diseases}

Lycopene had a protective effect on the oxidative stress-mediated damage of the human skin after irradiation with UV light (Ribaya-Mercado and others 1995).

\section{Aging and Cognition}

Oxidative stress and inflammation are considered significant mediators in healthy aging of the brain and in age-related neurodegenerative diseases such as Alzheimer's and Parkinson's disease (Shukitt-Hale and others 2006). Animal and human studies have suggested that fruits and vegetables have the potential to decrease some age-related processes, primarily due to the antioxidant and anti-inflammatory properties of several phytochemicals. An in vitro study has suggested that some classes of phytochemicals also act in cell signaling and thus may protect against aging by mechanisms other than oxidative and inflammatory processes (William and others 2004). Fruit and vegetable extracts have been demonstrated to reverse or retard various age-related cognitive and motor deficits in rats (Lau and others 2005).

Strawberry and spinach extracts attenuated age-related cognitive and neuronal decline in rats over 6-15 months, and blueberry extracts were effective in reversing existing cognitive deficits and improving motor function in aged rats (Joseph and others 2005). Examination of the brain tissue from these animals showed evidence of reduced inflammatory and oxidative processes in the supplemented groups. A transgenic mouse model of Alzheimer's disease fed blueberry extract exhibited cognitive performance equivalent to that of normal nonsupplemented mice and were significantly improved compared to nonsupplemented transgenic mice (Joseph and others 2003). Blueberry supplementation in the transgenic mice increased concentration of cell signaling kinases thought to be involved in converting short-term memory to long-term memory, and increased other aspects of cell signaling including increased muscarinic receptor activity that is also known to be important in cognitive function (Casadesus and others 2004). Aging rats provided with Concord grape juice at low concentration (10\%) for 9 weeks improved cognitive performance, while high (50\%) concentration improved motor performance (Shukitt-Hale and others 2006). Concord grape and juice contain a variety of flavonoids, and $10 \%$ grape juice supplementation was reported to be associated with the most effective increase in muscarinic receptor sensitivity in aging rats.

A study that interviewed 13,388 women living in 11 US states over a period of 10-16 years (Kang and others 2005) showed that baseline cognitive performance was stronger in women who reported the highest intake of cruciferous vegetables compared to those with lower intake.

It is believed that oxidative stress plays a key role in the development of Alzheimer's disease because of the characteristic lesions associated with free radical damage and the attenuation of these processes with supplementation of some antioxidants. To date, there are no clinical trials that specifically address the role of dietary fruits and vegetables, although there are trials to investigate the association between dietary antioxidants in food and risk of Alzheimer's disease. A study involving 5,395 men with an average age of 67.7 years, living in the Netherlands and followed for 6 years (Engelhart and others 2002), reported that baseline dietary intake of vitamin C and $\mathrm{E}$ as well as the use of antioxidant supplements was associated with reduced risk of 
developing Alzheimer's during the follow-up period, with a stronger protective effect in subjects who were smokers, and flavonoid and $\beta$-carotene intake was protective in smokers but not in nonsmokers.

\section{Nutritional and Health Importance of Some Fruits and Vegetables}

Fruits and vegetables are rich sources of phytochemicals, in addition to other components that may act synergistically with phytochemicals to contribute to the nutritional and health benefits of these food commodities.

\section{Apples and Pears}

Apples are a widely consumed, rich source of phytochemicals, including phenolic compounds, pigments, vitamin C, among others. There are six classes of polyphenols in apple fruit (Thompson and others 1972; Lea and Timberlake 1974; Whiting and Coggins 1975a, b; Lea 1978; Oleszek and others 1988; Spanos and others 1990). The anthocyanins and flavonol glycosides are mainly found in the skin. The phenolic acids are mainly chlorogenic and $p$-coumaroylquinic acid. The dihydrochalcones are phloretin glucoside (phloridzin) and xyloglucoside. The main catechin is (-)epicatechin, and the procyanidins are the $4-\beta$-8-linked epicatechin series with some mixed (+)-catechin/(-)-epicatechin. There is no significant amount of glutathione in apple fruit, and none in apple juice (Jones and other 1992). Fresh apple fruit may contain up to $100 \mathrm{ppm}$ of vitamin $\mathrm{C}$, but during processing into juice this is rapidly lost (Lea 1992). The phytochemical composition of apples varies greatly between different varieties, and it changes during maturation, ripening, storage, and processing (Curry 1997). The accumulation of antioxidants in apple peels before harvest was found to be affected more by ripening and light intensity than by low temperature (Barden and Bramlage 1994). Total antioxidant activity of apples is different depending on the cultivar; in one study, antioxidant capacity of four apple cultivars was in the order "Golden delicious" > "Empire" > "Delicious" > "Cortland" (Ju and Bramlage 1999).

Ascorbate and nonprotein thiol (glutathione) content significantly decreased with increasing maturity of pears (Pyrus communis L. cv. Conference; Lentheric and others 1999). Concomitantly, the activity of superoxide dismutase and catalase decreased about fivefold and twofold, respectively, when the fruit was picked more mature. Pears were reported to have lower antioxidant activity compared to pigmented fruits (Prior and Cao 2000). The antioxidant potentials measured by 1,1-diphenyl-2-picrylhydrazyl (DPPH), $\beta$-carotene bleaching, and nitric oxide inhibition radical scavenging tests in apple peel and pulp were significantly higher than in pear peel and pulp (Leontowicz and others 2003). The ethanol extract of apple peels showed the strongest inhibition of lipid peroxidation as a function of its concentration, pear pulp had the weakest antioxidant ability, whereas apple pulp and pear peel were equal (Leontowicz and others 2003). Diets supplemented with peels of both fruits exercised a significantly higher positive influence on plasma lipid levels and on plasma antioxidant capacity of rats than diets with fruit pulps (Leontowicz and others 2003).

In the laboratory, apples have been found to have very strong antioxidant activity, inhibit cancer cell proliferation, decrease lipid oxidation, and lower cholesterol (Boyer 
and Liu 2004). Epidemiological studies have linked the consumption of apples with reduced risk of some cancers, cardiovascular disease, asthma, and diabetes (Liu and others 2005). Apple extracts with 70\% acetone tested on the basis of their dry weight showed strong antioxidant activities toward oxidation of methyl linoleate, although apples were reported to be low in total phenolics (Kahkonen and others 1999). In apple juice, vitamin $\mathrm{C}$ activity represented a minor fraction of the total antioxidant activity with chlorogenic acid and phloretin glycosides as the major identifiable antioxidants (Miller and Rice-Evans 1997). Chlorogenic acid was found to contribute $27 \%$ of the total activity of apple extract to scavenge hydroxyl radicals (Plumb and others 1996b). It has been reported (Eberhardt and others 2000; Lee and others 2003) that the antioxidant and antiproliferative activities of apples are the consequences of synergistic activities of phenolics rather than vitamin $\mathrm{C}$. In pear fruit, the contribution of phenolic compounds to antioxidant activity has also been reported to be much greater than that of vitamin C (Galvis-Sanchez and others 2003). Phenolics in apple skin showed a much higher degree of contribution to the total antioxidant and antiproliferative activities of whole apple than those in apple flesh (Eberhardt and others 2000; Wolfe and others 2003). Some of the important antioxidant phenolics found in apples include chlorogenic acid, epicatechin, procyanidin $\mathrm{B}_{2}$, phloretin, and quercetin (Burda and others 1990; Mayr and others 1995). The relative antioxidant activity of some of these phenolic compounds in apples were in the order quercetin $>$ epicatechin $>$ procyanidin $>$ phloretin > vitamin C > chlorogenic acid (Lee and others 2003).

\section{Citrus}

Citrus fruit and their juices are rich sources of vitamin C, where one $8 \mathrm{fl}-\mathrm{oz}$ serving was reported to supply the entire Reference Daily Intake (RDI) amount for vitamin C (Rouseff and Nagy 1994). There is considerable variation in the vitamin C content of juices of different citrus fruits. Grapefruit, tangerine, and lemon generally contain between 20 and $50 \mathrm{mg} / 100 \mathrm{~mL}$ juice. Citrus limonoids (such as limonin and nomilin), one of the two main classes of compounds responsible for the bitter taste in citrus fruits, have certain biological activities that may be used as chemopreventive agents (Lam and others 1994). The main flavonoids in oranges and grapefruits are hesperidin and naringin, respectively, and hesperidin is also found in mandarins, lemons, and limes. The polymethoxyflavones and the glycosylated flavones are only found in citrus fruits, and their pattern is specific for each species; they have been shown to have a broad spectrum of biological activities such as anti-inflammatory, anticancer, and antiatherogenic properties ( $\mathrm{Li}$ and others 2009). Citrus flavonoids have been reported to possess anticancer activity both in vitro and in vivo (Middleton and Kandaswami 1994), in addition to antiviral and anti-inflammatory activities and an ability to inhibit human platelet aggregation (Huet 1982; Benavente-Garcia and others 1997). Citrus fruit are a particularly rich source of pectin, which occurs both in the edible portion and in the inedible residues such as peel, rag, and core (Baker 1994). Dietary incorporation of citrus pectins appears to affect several metabolic and digestive processes, such as glucose absorption, and cholesterol levels (Baker 1994).

Orange (Citrus sinensis) was found to be more active than pink grapefruit (Citrus paradisi) in scavenging peroxyl radicals, whereas grapefruit juice was more active than orange juice, when the oxygen radical antioxidant capacity (ORAC) assay was used 
(Wang and others 1996). Grapefruit extracts inhibited ascorbate-iron-induced lipid peroxidation of liver microsomes in a dose-dependent way, but were less effective antioxidant toward an NADH-iron induced system (Plumb and others 1996b). The total antioxidant activity in orange juice was thought to be accounted for by hesperidin and narirutin (Miller and Rice-Evans 1997). Seeds of lemons, sour orange, sweet orange, mandarins, and limes had greater antioxidant activity than the peels (Bocco and others 1998). Antioxidant activity is generally higher in the seeds than in the peels (Bocco and others 1998).

\section{Grapes and Berries}

Grapes and berries are rich sources of phytochemicals including phenolic compounds, pigments, and ascorbic acid.

Fresh grapes and grape juices are excellent sources of phenolic antioxidants (Frankel and Meyer 1998). Grapes and other dietary constituents derived from grapes, such as grape juice and wine, have attracted a great deal of attention in recent years, and therefore, the composition and properties of grapes have been extensively investigated. Grapes are considered one of the major sources of phenolic compounds among various fruits (Macheix and others 1990). The phenolic compounds found in Vitis vinifera include phenolic acids, stilbenes, and flavonoids, which include flavonols, flavanols, and anthocyanins, and play an important role in the quality of grapes and wines (Downey and others 2006). Anthocyanins are directly responsible for the color of grape fruit and young wines, whereas astringency of wines is related to catechins, proanthocyanidins, flavonols, and low-molecular-weight polyphenols (hydroxycinnamic and hydroxybenzoic acid derivatives); the latter also contribute to bitterness (Hufnagel and Hoffman 2008). The diverse classes and large amounts of phenolic compounds found in grapes (Somers and Ziemelis, 1985; Macheix and others, 1990; Ricardo-da-Silva and others, 1990) were reported to play an important role in human health, such as lowering of low-density lipoprotein (Frankel and others 1993; Tussedre and others 1996). It has been demonstrated that products derived from grapes have high antioxidant capabilities (Alonso and others 2002). In addition, viniferin, a potent antifungal agent, and anthocyanins, which are strong antioxidants that inhibit platelet aggregation, are also present in grapes (Escarpa and Gonzalez 2001). Extracts of fresh grapes inhibited human LDL oxidation from $22 \%$ to $60 \%$ and commercial grape juice from $68 \%$ to $75 \%$ when standardized at $10 \mu \mathrm{M}$ gallic acid equivalent (Frankel and others 1998). The LDL antioxidant activity correlated highly with the concentration of total phenolics for both grape extracts and commercial grape juices; with the level of anthocyanins and flavonols for grape extracts; with the levels of anthocyanins for Concord grape juices; and with the levels of hydroxycinnamates and flavan-3-ols in the white grape juice samples (Frankel and others 1998).

Berries contribute a significant number and amounts of phytochemicals such as ascorbic acid, carotenoids, flavonoids, phenolic acids, and tocopherols. Some wild berries with very high antioxidant activities include crowberry (Empetrum nigrum), cloudberry (Rubus chamaemorus), whortleberry (Vaccinium uliginosum), lingonberry (V. vitis-idaea), aronia (Aronia melanocarpa), cranberry (V. oxycoccus), and rowanberry (Sorbus aucuparia), but some of the cultivated berries such as strawberry (Fragaria ananassa), red currant (Ribes rubrum), black currant (Ribes nigrum), and 
raspberry (Rubus idaeus) exerted lower antioxidant activity (Kahkonen and others 1999). Different blueberries (V. corymbosum) and bilberries (V. myrtillus) were reported to exhibit good antioxidant activity in the ORAC assay (Prior and others 1998; Kalt and others 1999). The antioxidant capacity of blueberries was about threefold higher than either strawberries or raspberries with only a small contribution of ascorbic acid to the total antioxidant capacity compared to total phenolics and anthocyanins (Kalt and others 1999).

Strawberries are good sources of natural antioxidants (Heinonen and others 1998; Wang and others 1996). The extract of strawberries (F. ananassa) had the highest total antioxidant activity compared with extracts of plums, orange, red grapes, kiwi fruit, pink grapefruit, white grapes, banana, apple, tomato, pears, and honeydew melons when the ORAC assay was used (Wang and others 1996), but ranked among the least compared to some other berries when lipid oxidation models (methyl linoleate, LDL) assays were used (Heinonen and others 1998; Kahkonen and others 1999). Strawberry extracts exhibited high enzymatic activity for oxygen detoxification (Wang and others 2005) and a high level of antioxidant capacity against free radical species including peroxyl radicals, superoxide radicals, hydrogen peroxide, hydroxyl radicals, and singlet oxygen (Wang and Lin 2000; Wang and Jiao 2000). The major pigments of wild strawberries (F. vesca) were pelargonidin-3-monoglucoside and cyanidin-3-monoglucoside, whereas in cultivated strawberries the main pigment was only pelargonidin-3monoglucoside (Sondheimer and Karash 1956). Strawberry extracts exhibited chemopreventive and chemotherapeutic activities in vitro and in vivo (Carlton and others 2001; Meyers and others 2003; Wang and others 2005). They also inhibited proliferation of the human lung epithelial cancer cell line A549 and decreased tetradecanoylphorbol13-acetate (TPA)-induced neoplastic transformation of JB6 P+ mouse epidermal cells (Wang and others 2005).

\section{Avocados}

Avocado fruit is a high-fat fruit, contains rare sugars of high carbon number, and is relatively rich in certain vitamins, dietary fiber, minerals, and nitrogenous substances (Yahia 2009b). It has a high oil (3-30\%) and low sugar content (about 1\%); hence it is recommended as a high-energy food for diabetics (Yahia 2009b). It is a rich source of potassium, containing 1.6 times as much as bananas. A 100-g serving has about 177 calories, contains no cholesterol, and has about $17 \mathrm{~g}$ of fat, which is primarily monounsaturated type. Oil content is a key part of the sensory quality of the fruit. Oil quality is very similar to that of olive oil with a high proportion of the oil being approximately $75 \%$ monounsaturated, $15 \%$ saturated, and $10 \%$ polyunsaturated fatty acids. The high mono- and poly-unsaturation and low saturated content make it a "healthy" oil in terms of effect on heart disease. Monounsaturated fats in avocados have been reported to reduce blood cholesterol while preserving the level of highdensity lipoproteins. In addition, avocado oil contains a range of other health-promoting compounds such as chlorophyll, carotenoids, $\alpha$-tocopherol, and $\beta$-sitosterol. The edible portion of the fruit is rich in oleic, palmitic, linoleic, and palmitoleic acids, whereas stearic acid is present only in trace amounts. The fatty acid composition of the lipids of avocado fruit and avocado oil differs greatly with cultivar, stage of ripening, anatomical region of the fruit, and geographic location (Itoh and others 1975). However, the 
major fatty acid is always oleic followed by palmitic and linoleic acids, while the fatty acids present in trace amounts are myristic, stearic, linolenic, and arachidonic (Itoh and others 1975; Gutfinger and Letan 1974; Tango and others 1972; Mazliak 1971; Swicher 1984). The cuticular wax contains C20 to C27 long-chain fatty acids (Mazliak 1971). Avocados are rich in vitamin $B_{6}(3.9-6.1 \mu \mathrm{g} / \mathrm{g}$ pyridoxine) and contain lesser amounts of biotin, folic acid, thiamine, and riboflavin (Hall and others 1955), calciferol (vitamin D), $\alpha$-tocopherol (vitamin E), and 2-methyl-1,4-naphthoquinone (vitamin K) (Yahia 2009b). Therefore, besides being a source of energy and vitamins, avocado also contains several phytochemicals that are thought to be beneficial for health, and therefore it is considered by some as a "functional food" (Mazza 1998). Some nutraceutical ingredients that have been found in avocado pulp are antioxidants, such as tocopherols (about $4.3 \mathrm{UI} / 100 \mathrm{~g}$ ) and glutathione $(18 \mathrm{mg} / 100 \mathrm{~g})$. It has also been reported that avocado is a source of lutein (containing up to $248 \mathrm{mg} / 100 \mathrm{~g}$ ). The amount of $\beta$-sitosterol in this fruit is comparable to the level found in soy and olives. An avocado-enriched diet produced a significant reduction in low-density lipoproteins and total cholesterol in patients with high cholesterol levels, whereas diets enriched with soy and sunflower did not change the total cholesterol concentrations (Carranza and others 1997). Pigments are important contributors to the appearance and healthful properties of both avocado fruit and oil. Ashton and others (2006) identified in the skin, flesh, and oil of avocado fruit lutein, $\alpha$-carotene, $\beta$-carotene, neoxanthin, violaxanthin, zeaxanthin, antheraxanthin, $\mathrm{a}$ and $\mathrm{b}$ chlorophylls, and $\mathrm{a}$ and $\mathrm{b}$ pheophytins, with the highest concentrations of all pigments in the skin. Chlorophyllides $a$ and $b$ were identified in the skin and flesh tissues only.

\section{Stone fruits}

Yellow flesh peaches (Prunus persica L.), such as the cv "Fay Alberta," contain $54 \mathrm{RE} / 100 \mathrm{~g}$ of provitamin A carotenoids (USDA 1991), predominantly as $\beta$-carotene and $\beta$-cryptoxanthin (Gross 1987). The two dominant polyphenols (nonflavonoid) in sweet cherries (P. avium L.) are caffeoyltartaric acid and 3-p-coumaroylquinic acid (Robards and others 1999). However, sweet cherries are characterized to have anthocyanins as the major phenolic compounds, the aglicon cyanidin bound to the glycosides 3-rutinoside and 3-glucoside being the main compounds, and pelargonidin3-rutinoside, peonidin-3-rutinoside, and peonidin-3-glucoside as minor contributors (Gao and Mazza 1995; Chaovanalikit and Wrolstad 2004). Ascorbic acid, total phenolic compounds, and total antioxidant activity decreased during the early stages of sweet cherry fruit development, but exponentially increased coinciding with the stage of anthocyanin accumulation and fruit darkening (Serrano and others 2005). Prunes (Prunus domestica) and prune juice were antioxidant toward oxidation of human LDL (Donovan and others 1998). Prunes ranked highest with more than twice the level of antioxidants found in other high-scoring fruits, when the ORAC assay was used (Wang and others 1996). The inhibition of LDL oxidation by raw and canned peaches (Prunus persica) ranged between $56 \%$ and $87 \%$, with oxidation activity mainly attributed to the presence of hydroxycinnamic acids and chlorogenic and neochlorogenic acids, but not to carotenoids such as $\beta$-carotene and $\beta$-cryptoxanthin. However, Plumb and others (1996b) reported that hydroxycinnamic acids do not contribute to the inhibition of 
lipid peroxidation of liver and cell microsomes by fruit extracts including plums and peaches, although these fruits had the ability to scavenge hydroxyl radicals.

\section{Tropical Fruits}

Tropical fruits are important sources of nutrients (Yahia 2006). Bananas, plantains, and breadfruit are widely used as a source of starch, acerola fruit contains the highest known ascorbic acid content among all fruits (1,000-3,300 mg/100 $\mathrm{g}$ fresh weight), and some other good sources of vitamin $\mathrm{C}$ include guava, lychee, papaya, and passion fruit (Yahia 2006). Mango and papaya are good sources of vitamin A, breadfruit and cherimoya contain relatively high amounts of niacin and thiamin, and most tropical fruit are good sources of minerals, especially potassium and iron (Yahia 2006). Tropical fruits are thought to contain more carotenoids compared to temperate fruits, which contain more anthocyanins. Mango and papaya are among the tropical fruits rich in carotenoids (Rivera-Pastarna and others 2009; Ornelas-Paz and others 2007, 2008).

Mango fruit is a rich source of vitamin $\mathrm{C}$ and carotenoids, some of which function as provitamin A (Siddappa and Bhatia 1954; Thomas 1975, Yahia and others 2006). $\beta$-Carotene (all-trans), $\beta$-cryptoxanthin (all-trans and -cis), zeaxanthin (alltrans), luteoxanthin isomers, violaxanthin (all-trans and-cis), and neoxanthin (all-trans and -cis) were identified in several mango cultivars (Mercadante and others 1997; Ornelas-Paz and others 2007, 2008). Mango retinol was found to be highly bioavailable by estimating vitamin A and carotene reserves in the liver and plasma of rats. Information on the tocopherol content in mango is very scarce, but it seems to be low (Burns and others 2003; Ornelas-Paz and others 2007).

Some chemical components of Carica papaya fruit pulp have been reported by Oloyede (2005), suggesting that the astringent action of the plant encountered in numerous therapeutic uses is due to the presence of some phytochemicals such as saponins and cardenolides. Liquid chromatography-mass spectrometry analyses of ripe and green papaya showed few candidate phenols, other than catechin conjugates (Mahattanatawe and others 2006), which is consistent with the small number of compounds reported previously in this fruit (Agrawal and Agrawal 1982). Quercetin and kaempferol, previously reported in leaves and shoots of C. papaya (Canini and others 2007), were found only in trace amounts in fruit peel extracts (Canini and others 2007; Miean and Mohamed 2001). Corral-Aguayo and others (2008) reported that the antioxidant capacity of papaya extract ranked one of the lowest among eight different fruits.

Dopamine, a strong water-soluble antioxidant, was identified in banana fruit (Musa cavendishii) by Kanazawa and Sakakibara (2000). Banana fruit contained high levels in the pulp and peel: $2.5-10 \mathrm{mg} / 100 \mathrm{~g}$ and $80-560 \mathrm{mg} / 100 \mathrm{~g}$, respectively. A banana water extract was reported to suppress the autoxidation of linoleic acid by $65-70 \%$ after a 5-day incubation in an emulsion system, as determined from peroxide value and thiobarbituric acid reactivity (Kanazawa and Sakakibara 2000).

Pineapple fiber showed higher (86.7\%) antioxidant activity than orange peel fiber (34.6\%), and myricetin was the major polyphenol identified in pineapple fiber (Larrauri and others 1997).

Ma and others (2004) isolated and identified seven phenolic compounds in Pouteria campechiana, $P$. sapota, and $P$. viridis, namely, gallic acid, (+)-gallocatechin, 
$(+)$-catechin, (-)-epicatechin, dihydromyricetin, (+)-catechin-3-O-gallate, and myricitrin. The highest level of the seven phenolic compounds was found in $P$. sapota, the second highest in P. viridis, and the lowest in P. campechiana.

\section{Nuts}

Several nuts are among the dietary plants with high content of total antioxidants. Of the tree nuts, walnuts, pecans, and chestnuts have the highest contents of antioxidants. Walnuts contain more than $20 \mathrm{mmol}$ antioxidants per $100 \mathrm{~g}$, mostly in the walnut pellicles. Peanuts also contribute significantly to dietary intake of antioxidants (Blomhoff and others 2006). Almonds are rich sources of proteins, dietary fats, fibers, and several minerals (Ren and others 1993; Turnball and others 1993). Nine phenolic compounds have been identified in almonds by Sang and others (2002), of which eight exhibited strong antioxidant activity. Almond skins were found to contain high levels of four different types of flavanol glycosides, which are thought to have powerful effects as antioxidants (Frison and Sporns 2002). Polyphenolic compounds in almonds were reported to be absorbed well in the body and are active in preventing the oxidation of LDL cholesterol; vitamin $\mathrm{E}$ in almonds acts in synergy with phenolic compounds to reduce oxidation (Millburry and others 2002). Individuals who replaced half of their daily fat intake with almonds or almond oil for a period of 6 weeks showed reduced total and LDL cholesterol by $4 \%$ and 6\%, respectively, and HDL cholesterol increased by 6\% (Hyson and others 2002). Research has suggested a possible effect of almond consumption on cancer (Davis and Iwahashi 2000), including colon cancer (Davis and others 2003).

\section{Tomatoes}

Tomato and tomato-based products are considered healthy foods because they are low in fat and calories, cholesterol-free, and a good source of fiber, vitamins A and C, $\beta$-carotene, lycopene, and potassium (Yahia and Brecht 2009). The interest in the nutritional and health benefits of tomato fruit and their products has increased greatly (Geeson and others 1985; Giovannucci and Clinton 1998; Guester 1997; Yahia and Brecht 2009). Vitamin C content in tomato $(23 \mathrm{mg} / 100 \mathrm{~g})$ is not as high as in several other fruits, but its contribution is very important because of the common use of tomato in the diet of many cultures. A 100-g tomato can supply about $20 \%$ and $40 \%$ of the adult US recommended daily intake of vitamins A and C, respectively. The selection of tomato genotypes that are rich in vitamins $\mathrm{A}$ and $\mathrm{C}$ has been accomplished, and cultivars with very high vitamin A content have been developed, but their orange color was not highly accepted by consumers. Epidemiological studies indicated that tomato fruit had one of the highest inverse correlations with cancer risk and cardiovascular disease, including stroke (Giovannucci and others 1995). Lycopene, the principal pigment responsible for the characteristic deep-red color of ripe tomato fruit and tomato products, is a natural antioxidant that can prevent cancer and heart disease (Shi and Le Maguer 2000). Although lycopene has no provitamin A activity, as is the case with some other carotenoids, it does exhibit a physical quenching rate constant with singlet oxygen almost twice as high as that of $\beta$-carotene.

Increasing clinical evidence supports the role of lycopene as a micronutrient with important health benefits, due to its role in the protection against a broad range of 
epithelial cancers (Shi and Le Maguer 2000). The serum level of lycopene and the dietary intake of tomatoes have been inversely correlated with the incidence of cancer (Helzlsouer and others 1989; VanEenwyk and others 1991).

Fresh tomato fruit contains about 0.72 to $20 \mathrm{mg}$ of lycopene per $100 \mathrm{~g}$ of fresh weight, which accounts for about $30 \%$ of the total carotenoids in plasma (Stahl and Sies 1996). In contrast to other pigments such as $\beta$-carotene, lutein, violaxanthin, auroxanthin, neoxanthin, and chlorophylls a and $b$, which accumulate in inner pulp and in the outer region of the pericarp, lycopene appears only at the end of the maturation period and almost exclusively in the external part of the fruit (Laval-Martin and others 1975). Other tomato components that can contribute to health include flavonoids, folic acid, and vitamin E (Dorais and others 2001a,b).

Tomato was reported to exert antioxidant activity in some studies (Vinson and others 1998; Kahkonen and others 1999), whereas it showed no antioxidant activity or even acted as a pro-oxidant in others (Gazzani and others 1998). The antioxidant effect of tomato is most probably due to synergism between several compounds and not due to lycopene content alone, as pure lycopene and several other carotenoids act as pro-oxidants in a lipid environment (Al-Saikhan and others 1995; Haila and others 1996).

\section{Cruciferous Vegetables}

Sulfur-containing phytochemicals of two different kinds are present in all Brassica oleracea (Cruciferae) vegetables (cabbage, broccoli, cauliflower, Brussels sprouts, kale): (1) glucosinolates (previously called thioglucosides) and (2) $S$-methylcysteine sulfoxide. These compounds, which are derived in plant tissue by amino acid biosynthesis, show quite different toxicological effects and appear to possess anticarcinogenic properties (Stoewsand 1995). Glucosinolates have been extensively studied since the mid-nineteenth century. They are present in plant foods besides Brassica vegetables with especially high levels in a number of seed meals fed to livestock. About 100 different kinds of glucosinolates are known to exist in the plant kingdom, but only about 10 are present in Brassica. The first toxic effects of isothiocyanates and other hydrolytic products from glucosinolates that were identified were goiter and a general inhibition of iodine uptake by the thyroid. Numerous studies have indicated that the hydrolytic products of at least three glucosinolates, 4-methylsulfinylbutyl (glucoraphanin), 2-phenylethyl (gluconasturtiin), and 3-indolylmethyl (glucobrassicin), have anticarcinogenic activity. Indole-3-carbinol, a metabolite of glucobrassicin, has shown inhibitory effects in studies of human breast and ovarian cancers. $S$-Methylcysteine sulfoxide and its metabolite methylmethane thiosulfinate were shown to inhibit chemically induced genotoxicity in mice. Thus, the cancer chemopreventive effects of Brassica vegetables that have been shown in human and animal studies may be due to the presence of both types of sulfur-containing phytochemicals (i.e., certain glucosinolates and $S$-methylcysteine sulfoxide).

The effect of consumption of Brussels sprouts on levels of 8-oxo-7,8-dihydro$2^{\prime}$-deoxyguanosine (8-oxodG) in human urine was investigated in ten healthy, male, nonsmoking volunteers by Verhagen and others (1995). Following a 3-week runin period, five volunteers continued on a diet free of cruciferous vegetables for a subsequent 3-week intervention period (control group), while the other five (sprouts 
group) consumed $300 \mathrm{~g}$ of cooked Brussels sprouts per day, at the expense of $300 \mathrm{~g}$ of a glucosinolate-free vegetable. In the control group there was no difference between the two periods in levels of 8 -oxodG $(P=0.72)$, but in contrast, in the sprouts group the levels of 8 -oxodG were decreased by $28 \%$ during the intervention period $(P=$ 0.039), and therefore these results support the results of epidemiologic studies that consumption of cruciferous vegetables may result in a decreased cancer risk.

Extracts from broccoli (Brassica oleracea L. cv. Italica), Brussels sprouts (B. oleracea L. cv. Rubra), white cabbage (B. oleracea L. cv. Alba), and cauliflower (B. oleracea L. cv. Botrytis) showed significant antioxidant properties against lipid peroxidation (Plumb and others 1996a). However, it is thought that most of the direct antioxidant action of the cruciferous vegetables is not due to the glucosinolate content, but probably involves the hydroxylated phenols and polyphenol content, as has been identified in broccoli (Plumb and others 1997b). Cabbage, cauliflower, and Brussels sprouts were reported to be pro-oxidants toward lipid peroxidation in microsomes containing specific cytochrome P450s (Plumb and others 1997a). Kale (B. oleracea L. cv. Acephala), Brussels sprouts, and broccoli were found to exert higher antioxidant activity than cauliflower and some other vegetables (Al-Saikhan and others 1995; Cao and others 1996; Ramarathnam and others 1997; Vinson and others 1998).

\section{Leafy Vegetables}

Some contradictory results have been reported regarding the antioxidant activities of leafy vegetables. For example, among 23 vegetables, spinach (Spinacia oleracea L.) ranked 18th and head lettuce (Lactuca sativa L. cv. Capita) 22nd when assayed for inhibition of LDL (Vinson and others 1998). However, the ORAC antioxidant activity of spinach was reported to be very high, whereas that of leaf lettuce and iceberg lettuce was poor (Cao and others 1996).

\section{Root and Tuberous Vegetables}

Carrots (Daucus carota) are excellent sources of $\beta$-carotene and vitamin A, although they have been reported to exert low antioxidant activity compared to some other vegetables (Al-Saikhan and others 1995; Cao and others 1996; Ramarathnam and others 1997; Vinson and others 1998; Beom and others 1998). However, boiling carrots for 30 min significantly improved their antioxidant activity toward coupled oxidation of $\beta$-carotene and linolenic acid (Gazzani and others 1998).

In addition to being excellent source for some carbohydrates, potatoes (Solanum tuberosum) are considered a source for some antioxidants such as ascorbic acid, $\alpha$-tocopherol and polyphenolic compounds (Al-Saikhan and others 1995; Velioglu and others 1998). Potato peels have been reported to show high antioxidant activity (Rodriguez de Sotillo and others 1994). Purple potatoes and peel have been shown to exhibit greater antioxidant activities than the white and yellow varieties (Velioglu and others 1998), which is due to the presence of anthocyanins such as pelargonidin-3rutinoside-5-glucoside (Rodriguez-Saona and others 1998). Potato is not considered as a rich source of carotenoids, but some have been identified. Pendlington and others (1965) tentatively identified eight carotenoids (e.g., $\beta, \beta$-carotene, lutein) as most abundant in most cultivars, although Muller (1997) found that violaxanthin is the main potato carotenoid, followed by lutein, antheraxanthin, and others. Iwanzik and others (1983) 
compared the carotenoid content among 13 potato cultivars in the same habitat and reported violaxanthin as the main carotenoid, followed by lutein, lutein-5,6-epoxide, and neoxanthin. Breithaupt and Bamedi (2002) investigated the carotenoid pattern of four yellow- and four white-fleshed potato cultivars and reported that it was dominated by violaxanthin, antheraxanthin, lutein, and zeaxanthin, whereas neoxanthin, $\beta$-cryptoxanthin, and $\beta, \beta$-carotene generally were only minor constituents. The color of orange-fleshed potato was suggested to originate from large amounts of zeaxanthin (Brown and others 1993).

In addition of having some important phytochemicals such as betalains, beetroot (Beta vulgaris $\mathrm{L}$.) and sugar beet (Beta vulgaris esculenta) peels showed remarkably high antioxidant activities (Kahkonen and others 1999). For example, beet ranked eighth among 23 vegetables assayed for inhibition of LDL oxidation (Vinson and others 1998).

\section{Peppers}

Fresh peppers are excellent sources of vitamins A and C, as well as neutral and acidic phenolic compounds (Howard and others 2000). Levels of these can vary by genotype and maturity and are influenced by growing conditions and processing (Mejia and others 1988; Howard and others 1994; Lee and others 1995; Daood and others 1996; Simmone and others 1997; Osuna-Garcia and others 1998; Markus and others 1999; Howard and others 2000). Peppers have been reported to be rich in the provitamin A carotenoids $\beta$-carotene, $\alpha$-carotene, and $\beta$-cryptoxanthin (Minguez-Mosquera and Hornero-Mendez 1994; Markus and others 1999), as well as xanthophylls (Davies and others 1970; Markus and others 1999). Bell peppers have been shown to exert low antioxidant activity (Al-Saikhan and others 1995; Cao and others 1996; Vinson and others 1998) or may even act as pro-oxidants (Gazzani and others 1998).

\section{Alliums}

Edible alliums, especially onions and garlic, have been an important part of the daily diet of several cultures for hundreds of years. In many cultures alliums were thought to have medicinal properties. Allium vegetables, such as onions, garlic, scallions, chives, and leeks, include high concentrations of compounds such as diallyl sulfide and allyl methyl trisulfide (Steinmetz and Potter 1996). These compounds have been shown to inhibit cell proliferation and growth, enhance the immune system, alter carcinogen activation, stimulate detoxification enzymes, and reduce carcinogen-DNA binding (Hatono and others 1996; Lin and others 1994; Lee and others 1994; Amagase and Milner 1993). Hageman and others (1997) studied the effects of supplemental garlic consumption on ex vivo production of benzo[ $a$ ]pyrene-DNA adducts in lymphocytes in a nonrandomized pilot study of nine men and observed that isolated lymphocytes from the blood of participants eating garlic ( $3 \mathrm{~g}$ raw garlic per day for 8 days) developed fewer adducts when incubated with benzo $[a]$ pyrene.

Selenium has been shown to possess antitumor activity in humans. Efforts to produce Se-enriched vegetables (including garlic and broccoli) with anticarcinogenic activity have been successful. A number of studies (Ip and others 1992; Ip and Lisk 1994) have shown that selenium-enriched garlic is an effective anticarcinogen. Whanger and others (2000) have suggested that Se-enriched ramps (Allium tricoccum, a wild leek species) 
appear to have potential for reduction of cancer in humans. There was approximately $43 \%$ reduction in chemically induced mammary tumors when rats were fed a diet with Se-enriched ramps. Bioavailability studies with rats indicated that Se in ramps was $15-28 \%$ more available for regeneration of glutathione peroxidase activity than inorganic Se as selenite.

Yellow and red onions (Allium cepa) were reported to be poor antioxidants toward oxidation of methyl linoleate (Kahkonen and others 1999) in contrast to their high antioxidant activity toward oxidation of LDL (Vinson and others 1998). Garlic (Allium sativum $\mathrm{L}$ ) was reported to have four times more antioxidant activity than onions when using the ORAC assay (Cao and others 1996).

\section{Prickly Pear Fruit and Cladodes}

Prickly pear fruit and cladodes are valued because of their high nutrient content, vitamins, and other health components (Yahia 2009a; Hegwood 1990).

Cladodes (called nopal in Mexico) are low in calories, high in fiber, and traditionally consumed as vegetable in Mexico and the southern region of the US. Nopal contains about $920 \mathrm{~g} / \mathrm{kg}$ water, $40-60 \mathrm{~g} / \mathrm{kg}$ fiber, $10-20 \mathrm{~g} / \mathrm{kg}$ proteins, and about $10 \mathrm{~g} / \mathrm{kg}$ minerals, primarily calcium. Vitamin C content is about $100-150 \mathrm{mg} / \mathrm{kg}$, and $\beta$-carotenes (provitamin A) are about $300 \mu \mathrm{g} / \mathrm{kg}$. Cladodes are used in various pharmaceutical applications for their therapeutic, dermatological, and medical properties. Ethanol extract of Opuntia ficus-indica shows potential analgesic and anti-inflammatory effects (Park and others 1998). Galati and others (2001) reported preventive and curative effects of $O$. ficus-indica cladodes preparations on rats affected by ethanol-induced ulcers. The cactus consumption gives rise to cytoprotection phenomena by breaking up the epithelial cells and stimulating an increase in mucus production. When $O$. ficus-indica cladodes are administered as a preventive therapy, they keep the gastric mucosa in a normal condition by preventing mucus dissolution caused by ethanol and favoring mucus production. An increase of mucus production is also observed during the course of the curative treatment. The treatment with $O$. ficus-indica cladodes provokes an increase in the number of secretory cells. Probably, the gastric fibroblasts are involved in the antiulcer activity.

The consumption of prickly pear cactus fruit is recommended for their beneficial and therapeutic properties (Yahia 2009a). Aqueous extracts of cactus pear fruit (O. ficus-indica L. Mill) was reported by Butera and others (2002) to possess a high total antioxidant capacity, expressed as Trolox equivalents, and exhibit a marked antioxidant capacity in several in vitro assays, including the oxidation of red blood cell membrane lipids and the oxidation of human LDLs induced by copper and 2,2'-azobis(2-amidinopropane hydrochloride). Antioxidant components reported by these authors included vitamin $\mathrm{C}$, negligible amounts of carotenoids, and vitamin E. However, Corral-Aguayo and others (2008) reported that the antioxidant capacity of extracts of prickly pear fruit ranked the lowest compared to seven other fruits. Some prickly pear fruit contains two betalain pigments, the purple-red betanin and the yellow indicaxanthin, both with radical-scavenging and reducing properties (Forni and others 1992; Fernandez-Lopez and Almela 2001; Stintzing and others 2002; Castellanos-Santiago and Yahia 2008). Qualitative and quantitative analysis of betalain pigments in ten cultivars/lines of prickly pear (Opuntia spp.) fruit were conducted with 
reverse phase high-performance liquid chromatography-diode array detection (HPLCDAD) coupled with electrospray mass spectrometry (ESI-MS) (Castellanos-Santiago and Yahia 2008). Betacyanins and betaxanthins were identified by comparison with the UV/Vis and mass spectrometric characteristics as well as the retention times of semisynthesized reference betaxanthins. Carotenoids and chlorophylls were also identified and quantified based on their molecular mass determined by applying HPLCDAD coupled with positive atmospheric pressure chemical ionization mass spectrometry (APCI-MS). A total of 24 known/unknown betalains were present in the studied prickly pear fruit, including 18 betaxanthins and 6 betacyanins. The ratio and concentration of betalain pigments are responsible for the color in the different cultivars, showing the highest betalain content in fruit of purple color, comparable to that found in red beet (Beta vulgaris L. cv. Pablo). All cultivars/lines had a similar carotenoid profile, in which lutein was the most abundant compound in "Camuesa," while neoxanthin was the most abundant compound in the line "21441." Chlorophyll a was the most abundant in all cultivars/lines with the highest quantity in "21441." Daily supplementation with $500 \mathrm{~g}$ cactus fruit (O. ficus-indica) pulp for 2 weeks greatly improved the oxidation stress status of healthy humans (Tesoriere and others 2004). The effects included remarkable reduction in plasma markers of oxidative damage to lipids, such as isoprostanes and malondialdehyde (MDA), an improvement in the oxidative status of LDL, considerably higher concentrations of major plasma antioxidants, and improvement in the redox status of erythrocytes. The fruit also enhances renal function (Cacioppo 1991).

Reports indicate that other parts of prickly pear cactus are also used in folk medicine as emollient, moisturizing, wound-healing, hypocholesterolemic, and hypoglycemic agents and in gastric mucosal diseases (Hegwood 1990; Frati and others 1990a, 1990b; Cruse 1973; Meyer and McLaughlin 1981; Harvala and others 1982; Camacho-Ibanez and others 1983; Brutsch 1990; Fernandez and others 1992, 1994; Yahia 2009a). In Sicilian folk medicine, a flower infusion has an effect generally defined as depurative, and in particular it is used because of its diuretic and relaxant action on the renal excretory tract (Arcoleo and others 1961, 1966; Sisini 1969). Therefore, it is stipulated that a flower infusion may help the expulsion of renal calculus. Galati and others (2002) reported that flower infusion shows a modest increase in diuresis and natriuresis. Treatment with cladode infusions increases diuresis but does not significantly influence the uric acid pattern. The fruit infusion instead had diuretic and antiuric activity. The diuretic action observed may depend on stimulation of the urinary tract and is linked to the activation of neurohumoral mechanisms, mediators of stimuli acting on glomerules, or the pyelo-ureteral peristalsis. These effects might be due to the influence that the electrolytes, present in considerable quantities in the plant, exert on renal epithelium. In particular, $O$. ficus-indica is rich in $\mathrm{K}^{+}$ions, which are present in concentrations of $548 \mathrm{mg} \mathrm{kg}^{-1}$ in the cladodes, $21.7 \mathrm{mg} \mathrm{kg}^{-1}$ in the flowers, and $18 \mathrm{mg} \mathrm{kg}^{-1}$ in the fruit (d'Aquino 1998).

\section{Mushrooms}

Some types of mushrooms contain moderate quantities of good-quality protein and are good sources of dietary fiber, vitamins C and B, and minerals (Breene 1990). Extensive clinical studies have demonstrated that some species have medicinal and therapeutic value, by injection or oral administration, in the prevention/treatment of 
cancer, viral diseases (influenza, polio), hypercholesterolemia, blood platelet aggregation, and hypertension (Breene 1990). It has been reported that the inclusion of cultivated mushrooms, particularly shiitake and enokitake, in the diet is likely to provide some protection against some manifestation of cancer (Mori and others 1987).

\section{Pickled Vegetables}

Roussin's red (dimethylthiotetranitrosodiiron) has been identified as a nonalkylating $N$-nitroso compound present in pickled vegetables from Linxian, a high-risk area for esophageal cancer in China (Cheng and others 1981). In vitro experiments showed that Roussin's red had no significant mutagenic and transforming activities at the doses used, but it did enhance transformation in $\mathrm{C} 3 \mathrm{H} / 10 \mathrm{TI} / 2$ cells initiated with 3-methylcholanthrene $(0.1 \mu \mathrm{g} / \mathrm{mL})$, and it decreased the number of sebaceous glands and increased the epidermal thickness in short-term skin tests. This indicated that Roussin's red resembled 12-O-tetradecanoylphorbol-13-acetate and may be considered a new naturally occurring tumor promoter. Examination of dietary data in relation to the place-of-birth-specific incidence rates showed positive associations of stomach cancer with consumption of rice, pickled vegetables, and dried/salted fish, and a negative association with vitamin C intake (Kolonel and others 1981). These results are consistent with the particular hypothesis that stomach cancer is caused by endogenous nitrosamine formation from dietary precursors, and that vitamin $\mathrm{C}$ may protect against the disease. Extracts of pickled vegetables commonly consumed in Linhsien County, a high-incidence area for esophageal cancer in northern China, were studied for mutagenicity ( $\mathrm{Lu}$ and others 1981). The liquid residue from ether extracts produced a dose-dependent increase of mutants in Salmonella typhimurium TA98 and TA100 strains; mutagenicity required the presence of a fortified liver microsomal activation system induced by Aroclor 1254 in adult male BD VI inbred rats. An amount of extract equivalent to $2.8 \mathrm{~g}$ fresh pickled vegetables produced sixfold ( 75 revertants/g) and twofold (45 revertants/g) increases in revertant frequencies in strains TA98 and TA100, respectively. Roussin's red methyl ester, a tetranitroso compound, $\left[(\mathrm{NO})_{2} \mathrm{Fe}\left(\mathrm{CH}_{3} \mathrm{~S}\right)\right]_{2}$, was isolated and identified from the ether extracts and was shown to be mutagenic in strain TA 100 in the presence of a liver activation system, producing 25 revertants $/ \mathrm{mmol}$. A type of Japanese mixed vegetable pickle was found to be mutagenic to Salmonella typhimurium strains TA100 and TA98 with S9 mix (Takahashi and others 1979). Its activity was one-sixth that of a similar Chinese pickle from Linhsien County, China. Mutagens in the Japanese pickle were isolated, purified, and identified; the main component was kaempferol, and a minor component was isorhamnetin. As flavonoids are ubiquitous in vegetables, kaempferol and isorhamnetin do not seem to be specific to the pickle. Whole pickles of each kind of vegetable used in the Japanese pickle were extracted with methanol and subjected to mutagenicity tests; extracts of all vegetables except carrots were slightly mutagenic, with green leaves of vegetables and yellow chrysanthemum flowers showing the highest specific activity.

\section{Enhancement of Phytochemicals in Fruits and Vegetables}

In addition to increasing the consumption of fruits and vegetables, the enhancement of the nutritional and health quality of fruits and vegetables is an important goal in 
the effort to improve global health and nutrition. Erbersdobler (2003) and Boeing and others (2004) advocated the intake of functional foods that are enriched with phytochemicals.

Several crop production techniques have been reported to enhance phytochemical content in several fruits and vegetables (Schreiner 2005). Several postharvest practices and techniques can also affect the content of phytochemicals (Beuscher and others 1999; Goldmann and others 1999; Huyskens-Keil and Schreiner 2004).

Genetic engineering can make a substantial contribution to improved nutrition in crops. The most famous example of using biotechnology to improve nutrition is the development of vitamin A enriched "golden" rice (Ye and others 2000). Biotechnology has also been applied to improvements in the nutritional quality of a range of fruit and vegetables (Dalal and others 2006), targeting protein quality and quantity, desirable fatty acids, vitamins and minerals, and antioxidants. Many vegetables and fruits contain significant amounts of protein but are deficient in particular amino acids, such as the case of potato, which is deficient in lysine, tyrosine, methionine, and cysteine, and therefore the introduction of a transgene encoding a seed albumin protein into potato resulted in tubers with sufficient quantities of all essential amino acids (Chakraborty and others 2000). Cassava has also been improved by introducing an artificial protein encoding a maximal content of all essential amino acids (Sautter and others 2006). Conventional breeding has resulted in similar successes, such as maize with higher quality protein that is enriched for lysine and tryptophan (Hoisington 2002). Polyunsaturated fatty acids have been implicated as being beneficial to human health. Enhancement of the $\gamma$-linoleic acid content of tomato was achieved through introduction of a gene encoding a $\Delta 6$ desaturase enzyme (Cook and others 2002). Plants, including fruits and vegetables, naturally contain a large array of antioxidants, including carotenoids, vitamins $\mathrm{C}$ and $\mathrm{E}$, and flavonoids, and efforts to increase the antioxidant content of fruits and vegetables have taken both breeding-based and transgenic approaches. Natural high-pigment mutants are available in tomato that can be used in breeding strategies (Long and others 2006), and wild accessions of tomato exhibit substantial metabolic diversity that may similarly be exploited (Fernie and others 2006). A series of introgression lines have been generated in cultivated tomato containing genomic segments of a wild tomato relative, and the population exhibited a broad range of phenotypes, including characteristics that have potentially important attributes related to health and nutrition. Analysis of these lines identified more than 800 quantitative trait loci (QTL) underlying levels of various metabolites including ascorbate and $\alpha$-tocopherol (Schauer and others 2006). Using structural flavonoid genes (encoding stilbene synthase, chalcone synthase, chalcone reductase, chalcone isomerase, and flavone synthase) from different plant sources, Schijlen and others (2006) were able to produce transgenic tomatoes accumulating new phytochemicals. Biochemical analysis showed that the fruit peel contained high levels of stilbenes (resveratrol and piceid), deoxychalcones (butein and isoliquiritigenin), flavones (luteolin-7-glucoside and luteolin aglycon), and flavonols (quercetin glycosides and kaempferol glycosides). These researchers have demonstrated that, because of the presence of the novel flavonoids, the transgenic tomato fruits displayed altered antioxidant profiles. In addition, total antioxidant capacity of tomato fruit peel with high levels of flavones and flavonols increased more than threefold. These results on genetic engineering of flavonoids in 
tomato fruit demonstrate the possibilities for changing the levels and composition of health-related polyphenols in a crop plant (Fraser and others 2007). Introduction of transgenes has been shown to increase antioxidant content of tomatoes (Bovy and others 2002; Fraser and others 2002). QTL for lycopene content and $\beta$-carotene content have been identified in carrot (Santos and Simon 2002), and varietal differences in antioxidant content of onion suggests the presence of genetic diversity that could be exploited by selective breeding (Yang and others 2004). Diaz de la Garza and others (2004) used genetic engineering to generate a tenfold increase in the folic acid content of ripe tomatoes. Substantial improvements can be made using marker-assisted and traditional breeding. The use of nontransgenic approaches such as TILLING (targeted induced local lesions in genomes) can allow for relatively easy identification of novel alleles in either mutagenized or natural populations. This technology was initially used in reverse genetic studies by plant biologists, and it is now being applied to crop improvement (Slade and Knauf 2005). Naturally occurring germplasm can provide a rich source of genetic variation, and it is likely that new strategies for improving the nutritional value of fruits and vegetables will result from screening for variation in nutritional and health composition in wild crops and the broadest possible spectrum of existing cultivars.

\section{Conclusions}

Accumulating evidence demonstrates that fruit and vegetable consumption has healthpromoting properties. Fruits and vegetables are rich sources of diverse phytochemicals. The majority of evidence linking fruit and vegetable intake to health continues to be observational, and data in some areas are still contradictory. Therefore, although it is evident that fruit and vegetable consumption is important for health, there are still needs for more controlled, clinical intervention trials in order to investigate and to confirm the effect of the consumption of fruits and vegetables on various diseases, as well as studies to reveal the mechanisms behind the effect of the different phytochemical components of fruits and vegetables.

\section{References}

Agrawal P and Agrawal GP. 1982. Alterations in the phenols of papaya fruits infected by Colletotrichum spp. Proc Indian Natl Sci Acad, Part B 48:422-426.

Agarwal S and Rao AV. 1998. Tomato lycopene and low density lipoprotein oxidation: a human dietary intervention study. Lipids 33:981-984.

Agudo A, Slimani N, Ocke MC, Naska A, Miller AB, Kroke A, Bamia C, Karalis D, Vineis P, Palli D, Bueno-de-Mesquita HB, Peeters PHM, Engeset D, Hjartaker A, Navarro C, Garcia CM, Wallstrom P, Zhang JX, Welch AA, Spencer E, Stripp C, Overvad K, Clavel-Chapelon F, Casagrande C and Riboli E. 2002. Consumption of vegetables, fruit and other plant foods in the European Perspective Investigation in Cancer and Nutrition (EPIC) cohorts from 10 European countries. Publi Health Nutr 5(6B):1179-1196.

Aldoori W and Ryan-Harschman M. 2002. Preventing diverticular disease. Review of recent evidence on high-fiber diets. Can Fam Phys 48:1632-1637.

Alonso AM, Guillen DA, Barroso CG, Puertas B and Gracia A. 2002. Determination of antioxidant activity of wine byproducts and its correlation with polyphenolic content. J Agric Food Chem 50:5832-5836.

Al-Saikhan MS, Howard LR and Miller JC Jr. 1995. Antioxidant activity and total phenolics in different genotypes of potato (Solanum tuberosum L). J Food Sci 60:341-343, 7. 
Amagase J and Milner JA. 1993. Impact of various sources of garlic and their constituents on 7,12dimethylbenz $[\alpha]$ anthracene binding to mammary cell DNA. Carcinogenesis 14:1627-1631.

American Dietetic Association. 2002. Health implications of dietary fiber. JADA 102:994-1000.

Ames BN, Gold LW and Willett WC. 1995. The causes and prevention of cancer. Proc Natl Acad Sci USA 92(12):5258-5265.

Antova T, Pattenden S, Nikiforov B, Leonardi G, Boeva B, Fletcher T, Rudnai P, Slachtova H, Tabak C, Zlotkowska R, Houthuijs D, Brunekreef B and Holikova J. 2003. Nutrition and respiratory health in six central and Eastern European countries. Thorax 58:231-236.

Arcoleo A, Ruccia M and Cusmano S. 1961. Sui pigmenti flavonici delle Opuntiae. Nota I. Isoranmetina dai fiori di $O$. ficus indica Mill. Ann Chim 51:751-758.

Arcoleo A, Ruccia M and Natoli MC. 1966. Beta-sitosterolo dai fiori di Opuntia ficus-indica Mill. (Cactaceae). Atti Accad Sci Lett Art (Palermo) 25:323-232.

Ashton OB, Wong M, McGhie TK, Vather R, Wang Y, Requejo-Jackman C, Ramankutty P and Woolf AB. 2006. Pigments in avocado tissue and oil. J Agric Food Chem 54(26):10151-10158.

Baker RA. 1994. Potential dietary benefits of citrus pectin and fiber. Food Technol 1994(November): 133-139.

Barcelo S, Gardiner JM, Gesher A and Chipman JK. 1996. CYP2E1-mediated mechanism of antigenotoxicity of the broccoli constituent of sulforaphane. Carcinogenesis 17:277-282.

Barden CL and WJ Bramlage. 1994. Accumulation of antioxidants in apple peels as related to postharvest factors and superficial scald susceptibility of the fruit. J Am Soc Hort Sci 119:264-269.

Bazzano LA, He J, Ogden GL, Loria C, Vupputuri S, Meyers L, Whelton PK. 2001. Legume consumption and risk of coronary heart disease in US men and women. Arch Intern Med 26:2573-2578.

Bazzano LA, He J, Ogden G, Vupputuri S, Loria C, Meyers L, Meyers L and Whelton PK. 2002. Fruit and vegetable intake and risk of cardiovascular disease in US adults: the first national health and nutrition examination survey epidemiologic follow-up study. Am J Clin Nutr 76:93-99.

Bazzano LA, Li TY, Joshipura KJ and Hu FB. 2008. Intake of fruit, vegetables, and fruit juices and risk of diabetes in women. Diabetes Care 31(7):1311-1317.

Benavente-Garcia O, Castillo J, Marin FR, Ortuno A and Del Rio JA. 1997. Uses and properties of citrus flavonoids. J Agric Food Chem 45:4505-4515.

Beom JL, Yong SL and Myung HC. 1998. Antioxidant activity of vegetables and their blends in ironcatalyzed model system. J Food Sci Nutr 3:309-314.

Bes-Rastrollo M, Martínez-González MA, Sánchez-Villegas A, de la Fuente Arrillaga C and Martínez JA. 2006. Association of fiber intake and fruit/vegetable consumption with weight gain in a Mediterranean population. Nutrition 22(5):504-511.

Beuscher R, Howard L and Dexter P. 1999. Postharvest enhancement of fruits and vegetables for improved human health. Hort Sci 34(7):1167-1170.

Blanck HM, Gillespie C, Kimmons JE, Seymour JD and Serdula MK. 2008. Trends in fruit and vegetable consumption among US men and women, 1994-2005. Prev Chronic Dis 5(2):A35.

Block G, Patterson B and Subar A. 1992. Fruit, vegetables, and cancer prevention. A review of epidemiological evidence. Nutr Cancer 18:1-29.

Blomhoff R, Carlsen MH, Andersen LF and Jacobs DR Jr. 2006. Health benefits of nuts: potential role of antioxidants. Br J Nutr 96 Suppl 2:S52-S60.

Bocco A, Guvelier ME, Richard H and Berset C. 1998. Antioxidant activity and phenolic composition of citrus peel and seed extracts. J Agric Food Chem 46:2123-2129.

Boeing H, Barth C, Kluge S and Walter D. 2004. Tumorentstehung-hemmende und fordende Ernahrungsfaktoren. In Deutsche Gesellschaft fur Ernahrung, editor. Ernahrungsbericht 2004. Bonn: DGE MedienService, pp. 235-282.

Boone CW, Kelloff GJ and Maolone WE. 1990. Identification of candidate cancer chemopreventive agents and their evaluation in animal models and human clinical trials: a review. Cancer Res 50:2-9.

Botterweck AA, van den Brandt PA and Goldbohm RA. 1998. A prospective cohort study on vegetable and fruit consumption and stomach cancer risk in The Netherlands. Am J Epidemiol 148(9):842-853.

Bovy A, de Vos R, Kemper M, Schijlen E, Almenar PM, Muir S, Collins G, Robinson S, Verhoeyen M, Hughes S, Santos-Buelga C and van Tunen A. 2002. High-flavonol tomatoes resulting from the heterologous expression of the maize transcription factor genes LC and C1. Plant Cell 14:2509-2526.

Boyer J and Liu RH. 2004. Apple phytochemicals and their health benefits. Nutr J 12(3):5. 


\section{Fruit and Vegetable Phytochemicals}

Breene WM. 1990. Nutritional and medicinal value of specialt muchrooms. J Food Prot 53(10):883-894.

Breinholt V, Hendricks J, Pereira C, Arbogast D and Bailey G. 1995. Dietary chlorophyllin is a potent inhibitor of aflatoxin $B_{1}$ hepatocarcinogenesis in rainbow trout. Cancer Res 55(1):57-62.

Breithaupt D and Bamedi A. 2002. Carotenoids and carotenoid esters in potato (Solanum tuberosum L.): new insight into an ancient vegetable. J Agric Food Chem 50:7175-7181.

Brevick A, Vollset S, Tell G, Refsum H, Ueland P, Locken E, Drevon C and Andersen L. 2005. Plasma concentration of folate as a biomarker for the intake of fruit and vegetables: the Hordaland Homocysteine Study. Am J Clin Nutr 81:434-439.

Brown CR, Edwards CG, Yang CP and Dean BB. 1993. Orange flesh trait in potato: inheritance and carotenoid content. J Am Soc Hort Sci 118:145-150.

Brutsch MO. 1990. Some lesser-known uses of the prickly pear (Opuntia spp.). Proceedings of Transkei and Ciskei Research Society Conference.

Bueline T, Cosma M and Appenzeller M. 2001. Diet acids and alkali influence calcium retention in bone. Osteoporosis Int 12:493-499.

Buiatti E, Palli D, Decarli A, Amadori D, Avellini C, Biachi S, Bonaguri C, Cipriani F, Cocco P and Giacosa A. 1990. A case-control study of gastric cancer and diet in Italy: II. Association with nutrients. Int J Cancer 45:896-901.

Burda S, Oleszek W and Lee CY. 1990. Phenolic compounds and their changes in apples during maturation and color change. J Agric Food Chem 38:945-948.

Burke J, Curran-Celentano J and Wenzel A. 2005. Diet and serum carotenoid concentrations affect macular pigment optical density in adults 45 yaers and older. J Nutr 135:1208-1214.

Burns J, Fraser PD and Bramley PM. 2003. Identification and quantification of carotenoids, tocopherols and chlorophylls in commonly consumed fruits and vegetables. Phytochemistry 62:939-947.

Butera D, Tesoriere L, Di Gaudio F, Bongiorno A, Allegra M, Pintaudi A, Kohen R and Livrea M. 2002. Antioxidant activities of Sicilian prickly pear (Opuntia ficus-indica) fruit extracts and reducing properties of its betalains: betanin and indicaxanthin. J Agric Food Chem 50:6895-6901.

Cacioppo O. 1991. Fico d'india e pitaya. Verona: L'informatore Agrario.

Camacho-Ibanez R, Meckes-Lozoya M and Mellado-Campos V. 1983. The hypoglycemic effect of Opuntia streptacantha studied in different animal experimental models. J Ethnopharmacol 7:175-181.

Campbell JK, Canene-Adams K, Lindshield BL, Boileau TW, Clinton SK and Erdman JW Jr. 2004. Tomato phytochemicals and prostate cancer risk. J Nutr 134(12 Suppl):3486S-3492S.

Canini A, Alesiani D, D'Arcangelo G and Tagliatesta P. 2007. Gas chromatography-mass spectrometry analysis of phenolic compounds from Carica papaya L. leaf. J Food Comp Anal 20:584-590.

Cao G, Sofic E and Prior RL. 1996. Antioxidant capacity of tea and common vegetables. J Agric Food Chem 44:3426-3431.

Carlton PS, Kresty LA, Siglin JC, Morse MA, Lu J, Morgan C and Stoner GD. 2001. Inhibition of $N$-nitrosomethylbenzylamine-induced tumorigensis in the rat esophagus by dietary freeze-dried strawberries. Carcinogen 3:441-446.

Carranza MJ, Herrera AJ, Alvizouri MM, Alvarado JM and Chávez CF. 1997. Effects of a vegetarian diet vs a vegetarian diet enriched with avocado in hypercholesterolemic patients. Arch Med Res 28(4):537-541.

Casadesus G, Shukitt-Hale B, Stellwagen H, Shu X, Lee H-G, Smith M and Joseph J. 2004. Modulation of hippocampal plasticity and cognitive behavior by short-term blueberry supplementation in aged rats. Nutr Neurosci 7:309-316.

Castellanos-Santiago E and Yahia EM. 2008. Identification and quantification of betalaines from the fruits of 10 Mexican prickly pear cultivars by high-performance liquid chromatography and electron spray ionization mass spectrometry. J Agric Food Chem 56:5758-5764.

Celik F and Topcu F. 2006. Nutritional risk factors for the development of chronic obstructive pulmonary disease (COPD) in male smokers. Clin Nutr 25(6):955-961.

Cerhan J, Saag K, Merlino L, Mikuls T and Criswell L. 2003. Antioxidant micronutrients and risk of rheumatoid arthritis in a cohort of older women Am J Epidemiol 157:345-354.

Chakraborty S, Chakraborty N and Datta A. 2000. Increased nutritive value of transgenic potato by expressing a nonallergenic seed albumin gene from Amaranthus hypochondriacus. Proc Natl Acad Sci USA 97:3724-3729.

Chaovanalikit A and Wrolstad RE. 2004. Total anthocyanins and total phenolics of fresh and processed cherries and their antioxidant properties. J Food Sci 69:FCT67-FCT72. 
Chen MF, Chen LiT and Boyce HW, Jr. 1995. Cruciferous vegetables and glutathione: their effects on colon mucosal glutathione level and colon tumor development in rats induced by DMH. Nutr Cancer 23(1):77-83.

Cheng SJ, Sala M, Li MH, Courtois I and Chouroulinkov I. 1981. Promoting effect of Roussin's red identified in pickled vegetables from Linxian China. Carcinogenesis 2:313-319.

Christen W, Liu S, Schaumberg D and Buring J. 2005. Fruit and vegetable intake and risk of cataract in women. Am J Clin Nutr 81:1417-1422.

Chu Y-F, Sun J, Wu X and Lui RH. 2002. Antioxidant and antiproliferative activities of common vegetables. J Agric Food Chem 50:6910-6916.

Colditz GA, Branch LG and Lipnic RJ. 1985. Increased green and yellow vegetables intake and lowered cancer death in an elderly population. Am J Clin Nutr 41:32-36.

Cook D, Grierson D, Jones C, Wallace A, West G and Tucker G. 2002. Modification of fatty acid composition in tomato (Lycopersicon esculentum) by expression of a borage delta6-desaturase. Mol Biotechnol 21:123-128.

Corral-Aguayo R, Yahia EM, Carrillo-Lopez A and Gonzalez-Aguilar G. 2008. Correlation between some nutritional components and the total antioxidant capacity measured with six different assays in eight horticultural crops. J Agric food Chem 56:10498-10504.

Crowell PL and Gould MN. 1994. Chemoprevention and therapy of cancer by D-limonine. Crit Rev Oncog 5:1-22.

Cruse R. 1973. Desert plant chemurgy: a current review. Econ Bot 27:210-230.

Curry EA. 1997. Effect of postharvest handling and storage on apple nutritional status using antioxidants as a model. HortTech 7(3):240-243.

Dalal M, Dani RG and Kumar PA. 2006. Current trends in the genetic engineering of vegetable crops. Scientia Hort 107:215-225.

Daood HG, Vinkler M, Markus F, Hebshi EA and Biacs PA. 1996. Antioxidant vitamin content of spice red pepper (paprika) as affected by technological and varietal factors. Food Chem 55:365-372.

d'Aquino A. 1998. Tesi per il conseguimento del Dottorato di Ricerca in Farmacognosia (IX Ciclo). Opuntia ficus indica Mill. Ricerche Farmacognostiche. Facolta di Farmacia- Universita di Messina.

Dashwood RH, Arbogst DN, Fong AT, Pereira C, Hendricks JD and Baily GS. 1989. Quantitative interrelationships between aflatoxin B1 carcinogen dose, indole-3-carbinol anto-carcinogen dose, target organ DNA adduction and final tumor response. Carcinogenesis 10:175-181.

Davies BH, Matthews S and Kirk JTO. 1970. The nature and biosynthesis of the carotenoids of different colour varieties of Capsicum annuит. Phytochemistry 9:797-800.

Davis P and Iwahashi CK. 2001. Whole almonds and almond fractions reduce aberrant crypt foci in a rat model of colon carcinogenesis. Cancer Letters 165:27-33.

Davis P, Iwahashi CK and Yokoyama W. 2003. Whole almonds activate gastrointestinal (GI) tract antiproliferative signaling in APCmin (multiple intestinal neoplasia) mice. FACEB J 17(5):AQ1153.

de Carvalho EB, Vitolo MR, Gama CM, Lopez FA, Taddei JA and de Morais MB. 2006. Fiber intake, constipation, and overweight among adolescents living in Sao Paulo City. Nutrition 22(7-8):744-749.

Devereux G and Seaton A. 2005. Diet as a risk factor for atopy and asthma. J Allergie Clin Inmunol 115:1109-1117.

Di Mascio P, Kaiser S and Sies H. 1989. Lycopene as the most efficient biological carotenoid singlet oxygen quencher. Arch Biochem Biophys 274:532-538.

Di Mascio P, Murphy MC and Sies H. 1991. Antioxidant defense systems, the role of carotenoid, tocopherol and thiols. Am J Clin Nutr 53 (Suppl):194-200.

Diaz de la Garza R, Quinlivan EP, Klaus SM, Basset GJ, Gregory JFR and Hanson AD. 2004. Folate biofortification in tomatoes by engineering the pteridine branch of folate synthesis. Proc Natl Acad Sci USA 101:13720-13725.

Donovan JL, Meyer AS and Waterhouse AL. 1998. Phenolic composition and antioxidant activity of prune juice. J Agric Food Chem 46:1247-1252.

Dorais M, Papadopoulos AP and Gosselin A. 2001a. Greenhouse tomato fruit quality. Hort Rev 26:239-319.

Dorais M, Papadopoulos AP and Gosselin A. 2001b. Influence of electric conductivity management on greenhouse tomato yield and fruit quality. Agronomie 21:367-383.

Dosil-Díaz O, Ruano-Ravina A, Gestal-Otero JJ and Barros-Dios JM. 2008. Consumption of fruit and vegetables and risk of lung cancer: a case-control study in Galicia, Spain. Nutrition 24(5):407-413. 
Downey MO, Dokoozlian NK and Krstic MP. 2006. Cultural practice and environmental impacts on the flavonoid composition of grapes and wine: a review of recent research. Am J Enol Vitic 57:257268.

Duthie GG, Duthie SJ and Kyle JAM. 2000. Plant polyphenols in cancer and heart disease: implications as nutritional antioxidants. Nutr Res Rev 13(1):79-106.

Eberhardt MV, Lee C and Liu RH. 2000. Antioxidant activity of fresh apples. Nature 405:903-904.

Eichholzer M, Tonz O and Zimmerman R. 2006. Folic acid: a public health challenge. Lancet 367:13521361.

Engelhart M, Geerlings M, Ruitemberg D, van Swieten J, Hoffman A, Wittman J and Breteler M. 2002. Dietary antioxidants and risk of Alzheimer's disease. JAMA 287; 3223-3229.

Erbersdobler H. 2003. Workstoffe. In: Erberdobler H and Meyer A, editors. Praxishandbuch Functional Food. Hamburg: B. Behr's Verlag, pp. 1-14.

Escarpa A and Gonzalez MC. 2001. An overview of analytical chemistry of phenolic compounds in foods. Crit Rev Anal Chem 31:57-139.

Farchi S, Forastieri F, Agabiti N, Corbo G, Pistelli R, Fortes C, Dell'Orco V and Perucci C. 2003. Dietary factors associated with wheezing and allergic rhinitis in children. Eur Respir J 22:772-780.

Fernandez LM, Lin ECK, Trejo A and McNamara DJ. 1992. Prickly pear (Opuntia sp.) pectin reverses low density lipoprotein receptor suppression induced by a hypercholesterolemic diet in Guinea Pigs. J Nutr 122:2330-2340.

Fernandez LM, Lin ECK, Trejo A and McNamara DJ. 1994. Prickly pear (Opuntia sp.) pectin alters hepatic cholesterol metabolism without affecting cholesterol absorption in guinea pigs fed a hypercholesterolemic diet. J Nutr 124:817-824.

Fernandez-Lopez JA and Almela L. 2001. Application of high performance liquid chromatography to the characterization of the betalain pigments in prickly pear fruits. J Chromatogr 913:415-420.

Fernie AR, Tadmor Y and Zamir D. 2006. Natural genetic variation for improving crop quality. Curr. Opin. Plant Biol 9:196-202.

Feskanich D, Ziegler RG, Michaud DS, Giovanucci EL, Speizer FE, Willett WC and Colditz GA. 2000. Prospective study of fruit and vegetable consumption and risk of lung cancer among men and women. Int J Natl Cancer Inst 92(22):1812-1823.

Forni E, Polesello A, Montefiori D and Maestrelli A. 1992. A high performance liquid chromatographic analysis of the pigments of blood-red prickly pear (Opuntia ficus-indica). J Chromatogr 593:177-183.

Franceschi S, Bidoli E, La Vecchis C, Talamini R, D’Avanzo B and Negri E. 1994. Tomatoes and risk of digestive-tract cancers. Int J Cancer 59:181-184.

Frankel EN, Bosanek CA, Mayer AS, Silliman K and Kirk LL. 1998. Commercial grape juices inhibit the in vitro oxidation of human low-density lipoproteins. J Agric Food Chem 46:834-838.

Frankel EN and Meyer AS. 1998. Antioxidants in grapes and grape juices and their potential health effects. Pharmaceutical Biol 36:1-7.

Frankel EN, Waterhouse AL and Kinsella JE. 1993. Inhibition of human LDL oxidation by resveratrol. Lancet 341:1103-1104.

Fraser PD, Enfissi EMA, Halket JM, Truesdale MR, Yu D, Gerrish C, Bramley PM. 2007. Manipulation of phytoene levels in tomato fruit: effects on isoprenoids, plastids, and intermediary metabolism. Plant Cell 19:3194-3211.

Fraser PD, Romer S, Shipton CA, Mills PB, Kiano JW, Misawa N, Drake RG, Schuch W and Bramley PM. 2002. Evaluation of transgenic tomato plants expressing an additional phytoene synthase in a fruit-specific manner. Proc Natl Acad Sci USA 99:1092-1097.

Frati, A. 1992. Medical implication of prickly pear cactus. In: Felker P and Moss JR, editors. Proceedings of the Third Annual Texas Prickly Pear Council, pp. 29-34. Kingsville, TX.

Frati AC, Gordillo BE, Altamirano P, Ariza CR, Cortes-Franco R and Chavez-Negrete A. 1990a. Acute hypoglycemic effect of Opuntia streptacantha Lemaire in NIDDM. Diabetes Care 13; 455-456.

Frati AC, Hernandez de la Riva H, Ariza CR and Torres MD. 1983. Effects of nopal (Opuntia sp.) on serum lipids, glycemia and body weight. Arch Invest Med (Mexico) 14:117-125.

Frati AC, Jimenez E and Ariza CR. 1990b. Hypoglycemic effect of Opuntia ficus-indica in non-insulin dependent diabetes mellitus patients. Phytother Res 4:195-197.

Frison S and Sporns P. 2002. Variation of the flavanol glycoside composition of almond seedcoats as determined by MALDI-TOF mass spectrometry. J Agric Food Chem 50(23):6818-6822. 
Galati EM, Pergolozzi S, Miceli N, Monforte MT and Tripodo MM. 2001. Study on the increment of production of gastric mucus in rats treated with Opuntia ficus-indica (L) Mill. cladodes. J Ethnopharmacol 83(3):229-233.

Galati EM, Tripodo, MM, Trovato A, Miceli N and Monforte MT. 2002. Biological effect of Opuntia ficus-indica (L) Mill (Cactacea) waste matter. Note I: diuretic activity. J Ethnopharmacol 79(1):17-21.

Galvis-Sanchez AC, Gil-Izquierdo A and Gil MI. 2003. Comparative study of six pear cultivars in terms of their phenolic and vitamin C contents and antioxidant capacity. J Sci Food Agric 83:995-1003.

Gandini S, Merzeninch H, Robertson C and Boyle P. 2000. Meta analysis of studies on breast cancer risk and diet: the role of fruit and vegetable consumption and the intake of associated micronutrients. Eur $\mathrm{J}$ Cancer 36:636-646.

Gao L and Mazza G. 1995. Characterization, quantification, and distribution of anthocyanins and colorless phenolic in sweet cherries. J Agric Food Chem 43:343-346.

Garcia-Solis P, Yahia EM and Aceves C. 2008. Study of the effect of 'Ataulfo' mango (Mangifera indica L) intake on mammary carcinogenesis and antioxidant capacity in plasma of $N$-methyl-nitrosourea (MNU)treated rats. Food Chem 111:309-315.

Garcia-Solis P, Yahia EM, Morales-Tlalpan V and Diaz-Munoz M. 2009. Screening of antiproliferative effect of aqueous extracts of plant foods in Mexico on the breast cancer cell line MCF-7. Int J Food Sci Nutr. In press.

Gazzani G, Pappeti A, Massolini G and Daglia M. 1998. Anti- and prooxidant activity of water soluble components of some common diet vegetables and the effect of thermal treatment. J Agric Food chem. 46:4118-4122.

Geeson JD, Browne KM, Maddison K, Sheferd J and Guaraldi F. 1985. Modified atmosphere packaging to extend the shelf life of tomatoes. J Food Technol 20:339-349.

Gerster H. 1997. The potential role of lycopene for human health: review article. J Am Coll Nutr 16:109-126.

Giovannucci E. 1999. Tomatoes, tomato-based products, lycopene, and cancer: review of the epidemiologic literature. J Natl Cancer Inst 91(4):317-331.

Giovannucci E, Ascherio A, Rimm EB, Stampfer MJ, Colditz GA and Willett WC. 1995. Intake of carotenoids and retinol in relation to risk of prostate cancer. J Natl Cancer Inst 87:767-776.

Giovannucci E and Clinton SK. 1998. Tomatoes, lycopene, and prostate cancer. Proc Soc Exp Biol Med 218(2):129-139.

Giovannucci E, Rimm EB, Liu Y, Stampfer MJ and Willett WC. 2003. A prospective study of cruciferous vegetables and prostate cancer. Cancer Epidimiol Biomarkers Prev 12(12):1403-1409.

Goldberg I. 1994. Introduction. In: Goldberg I, editor. Functional Foods: Designer Foods, Pharmafoods, Nutraceuticals. New York: Chapman and Hall, pp. 1-16.

Goldmann IL, Kader AA and Heintz C. 1999. Influence of production, handling, and storage on phytonutrient content of foods. Nutr Rev 57:46-52.

Goodman MT, Kolonel TJ, Wilkens, LR, Yoshizawa CN, Le Marchand L and Hankin JH. 1992. Dietary factors in lung cancer prognosis. Eur J Cancer 28:495-501.

Graham S, Dayal H, Swanson M, Mittelman A and Wilkinson G. 1978. Diet in the epidemiology of cancer of the colon and rectum. J Natl Cancer Inst 61:709-714.

Graham S and Mettlin C. 1981. Fiber and other constituents of vegetables in cancer epidemiology. Progr Cancer Res Ther 17:189-215.

Gross J. 1987. Pigments in Fruits. London: Academic Press.

Grube BJ, Eng ET, Yeh CK, Kwon A and Shiuan C. 2001. White button mushroom phytochemicals inhibit aromatase activity and breast cancer cell proliferation. J Nutr 13:3288-3293.

Guester H. 1997. The potential role of lycopene for human health. J Am Clin Nutr 16:109-126.

Gutfinger T and Letan A. 1974. Studies of unsaponificables in several vegetable oils. Lipids 9:658.

Hageman G, Krul C, van Herwinjnen M, Schilderman P and Kleinjans J. 1997. Assessment of the anticarcinogenic potential of raw garlic in humans. Cancer Lett 114:161.

Haila KM, Lievonen SM and Heinon IM. 1996. Effects of lutein, lycopene, annatto, and $\gamma$-tocopherol on oxidation of triglycerides. J Agric Food Chem 44:2096-2100.

Hall AP, More JF and Morgan AF. 1955. A vitamin content of California grown avocados. J Agric Food Chem 3:250-252.

Hamer M and Chida Y. 2007. Intake of fruit, vegetables, and antioxidants and risk of type 2 diabetes: systematic review and meta-analysis. J Hypertens 25(12):2361-2369. 
Harwood M, Danielewska-Nikiel B, Borselleca JF, Flamm GW, Williams GM and Lines TC. 2007. A critical review of the data related to the safety of quercetin and lack of evidence of in vivo toxicity, including lack of genotoxic/carcinogenic properties. Food Chem Toxicol 45:2179-2205.

Harvala C, Alkofahi A and Philianos S. 1982. Sur l'action enxymatique d'un produit extrait des graines d'Opuntia ficus-indica Miller. Plant Meedic Phitotherap 4:298-302.

Hatono S, Jimenez A and Wargovich MJ. 1996. Chemopreventive effect of $S$-allylcysteine and its relationship to the detoxification enzyme glutathione $S$-transferase. Carcinogenesis 17:1041-1044.

He K, Hu FB, Colditz GA, Manson JE, Willett WC and Liu S. 2004. Changes in intake of fruits and vegetables in relation to risk of obesity and weight gain among middle-aged women. Int J Obes Relat Metab Disord 28(12):1569-1574.

Hegwood DA. 1990. Human health discoveries with Opuntia sp. (prickly pear). Hort Sci 25(12):1515-1516.

Heinonen IM, Meyer AS and Frankel EN. 1998. Antioxidant activity of berry phenolics on human lowdensity lipoprotein and liposome oxidation. J Agric Food Chem 46:4107-4112.

Helzlsouer KJ, Comstock GW and Morris JS. 1989. Selenium, lycopene, alpha tocopherol, beta carotene, retinol, and subsequent bladder cancer. Cancer Res 49:6144-6148.

Hennekens CH, Burig JE, Manson JE, Stampfer M, Rosner B, Cook NR, Belanger C, LaMotte F, Gaziano JM, Ridker PM, Willett W and Peto R. 1996. Lack of effect of long-term supplementation with beta carotene on the incidence of malignant neoplasms and cardiovascular disease. N Engl J Med 334:1145-1149.

Hirayama T. 1990. Lifestyle and Mortality. Contributions to epidemiology and Biostatistics, Volume 6. Basel, Switzerland: Karger.

Hoisington D. 2002. Opportunities for nutritionally enhanced maize and wheat varieties to combat protein and micronutrient malnutrition. Food Nutr Bull 23:376-377.

Howard LR, Smith RT, Wagner AB, Villalon B and Burns EE. 1994. Provitamin A and ascorbic acid content of fresh pepper cultivars (Capsicum annuum) and processed jalapenos. J Food Sci 59:362-365.

Howard LR, Talcott ST, Brenes CH and Villalon B. 2000. Changes in phytochemical and antioxidant activity of selected pepper cultivars (Capsicum species) as influenced by maturity. J Agric Food Chem 48:1713-1720.

Howe G, Hirohata T, Hislop T, Iscovich J, Yuan J, Katsouyanni K, Lubin F, Marubini E, Modan B, Rohan T, Toniolo P and Shunzhang Y. 1992. Dietary factors and risk of breast cancer: combined analysis of 12 case-control studies. J Nat Cancer Inst 82:561-569.

Huet R. 1982. Constituents of citrus fruits with pharmacodynamic effects: citroflavonoids. Fruits 37:267-71.

Hufnagel JC and Hofmann T. 2008. Orosensory-directed identification of astringent mouth feel and bittertesting compounds in red wine. J Agric Food Chem 56:1376-1386.

Hung HC, Merchant A, Willett W, Ascherio A, Rosner BA, Rimm E and Joshipura KJ. 2003. The association between fruit and vegetable consumption and peripheral arterial disease. Epidemiology 14(6):659665 .

Huyskens-Keil S and Schreiner M. 2004. Quality dynamics and quality assurance of fresh fruit and vegetables in pre- and postharvest. In: Dris R and Jain S, editors. Production Practices and Quality Assessment of Food Crops. Dordrecht: Kluwer Academic, pp. 401-449.

Hyson DA, Scheeman BO and Davis PA. 2002. Almonds and almond oil have similar effects on plasma lipid and LDL oxidation in healthy men and women. J Nutr 132(4):703-707.

Ip C, Lisk DJ. 1994. Enrichment of selenium in allium vegetables for cancer prevention. Carcinogenesis 15:1881-1885.

Ip C, Lisk DJ and Stoewasand GS. 1992. Mammary cancer prevention by regular garlic and selenium enriched garlic. Nutr Cancer 17:279-286.

Itoh T, Tamura T, Matsumato T and Dupaigne P. 1975. Studies on avocado oil in particular on the unsaponifiable sterol fraction. Fruits 30:687-695.

Iwanzik W, Tevini M, Stute R and Hilbert R. 1983. Carotinoidgehalt und Zusammensetzung verschiedener deutscher karto isorten und deren Bedeutung fur die Fleischfarbe der Knolle. Pot Res 26:149-162.

Jajoo R, Song L, Rasmussen H, Harris S and Dawson-Hughes B. 2006. Dietary acid-base balance, bone resorption and calcium excretion. J Nutrition 25:223-230.

Jenkins DJ, Hu FB, Tapsell LC, Josse AR and Kendall CW. 2008. Possible benefit of nuts in type 2 diabetes. J Nutr 138(9):1752S-1756S.

Johnston CS, Taylor CA and Hampl JS. 2000. More Americans are eating "5 a day" but intakes of dark green and cruciferous vegetables remain low. J Nutr 130(12):3063-3067. 
Jones DP, Coates RJ, Flagg EW, Eley JW, Block G, Greenberg RS, Gunter EW and Jackson B. 1992. Glutathione in foods listed in the National Cancer Institute's health habits and history food frequency questionnaire. Nutr Cancer 17(1):57-75.

Joseph J, Arendash G, Gordon M, Diamond D, Shukitt-Hale B and Morgan D. 2003. Blueberry supplementation enhances signaling and prevents behavioral deficits in an Alzheimer disease model. Nutr Neurosci 6:153-163.

Joseph J, Shukitt-Hale B, Casadesus G and Fisher D. 2005. Oxidative stress and inflammation in brain aging: nutritional considerations. Neurochem Res 30:927-935.

Joshipura K, Hu F, Manson J, Stamfer M, Rimm E, Speizer F, Coltiz G, Asherio A, Rosner B, Spiegelman $\mathrm{D}$ and Willett W. 2001. The effect of fruit and vegetable intake on risk on coronary heart disease. Ann Int Med 134:1106-1114.

Ju Z and WJ Bramlage. 1999. Phenolics and lipid-soluble antioxidants in fruit cuticle of apples and their antioxidant activities in model systems. Postharv Biol Technol 16:107-118.

Jung KJ, Wallig MA and Singletary KW. 2006. Purple grape juice inhibits 7,12-dimethylbenz[a]anthracene (DMBA)-induced rat mammary tumorigenesis and in vivo DMBA-DNA adduct formation. Cancer Lett 233:279-288

Kahkonen MP, Hopia AI, Vurela HJ, Rauha J-P, Pihlaja K, Kujala TS and Heinon M. 1999. Antioxidant activity of plant extracts containing phenolic compounds. J Agric Food Chem 47:3954-3962.

Kalt W, Forney CF, Martin A and Prior RL. 1999. Antioxidant capacity, vitamin C, and anthocyanins after fresh storage of small fruits. J Agric Food Chem 47:4638-4644.

Kanazawa K and Sakakibara H. 2000. High content of dopamine, a strong antioxidant, in Cavendish banana. J Agric food Chem 48:844-848.

Kang J, Asherio A and Grodstein F. 2005. Fruit and vegetable consumption and cognitive decline in aging women. Am Neurol 2005:713-720.

Kelloff GJ, Boone CW, Crowell JA, Steele VE, Lubet RA, Doody LA, Maolone WF, Hawk ET and Sigman CC. 1996. New agents for cancer chemoprevention. J Cell Biochem 26s:1-28.

Kelly Y, Sacker A and Marmot A. 2003. Nutrition and respiratory health in adults: findings from the Health Survey for Scotland. Eur Respir J 21:664-671.

Kirsh VA, Peters U, Mayne ST, Subar AF, Chatterjee N, Johnson CC and Hayes RB. 2007. Prospective study of fruit and vegetable intake and risk of prostate cancer. J Natl Cancer Inst 99(15):12001209.

Kolonel LN, Nomura MY, Hirohata T, Hankin JH and Hinds MW. 1981. Association of diet and place of birth with stomach cancer incidence in Hawaii Japanese and Caucasians. Am J Clin Nutr 34(11):24782485.

Kotake-Nara E, Kushiro M, Hong Z, Sugawara T, Miyashita K and Nagao A. 2001. Carotenoids affect proliferation of human prostate cancer cells. J Nutrition 131(12):3303-3306.

Kris-Etherton P, Hecker K, Bonanome A, Coval S, Binkoski A, Hilpert K, Griel A and Etherton T. 2002. Bioactive compounds in foods: their role in the prevention of cardiovascular disease and cancer. Am J Med 113:71-88.

Kris-Etherton PM, Hu FB, Ros E and Sabaté J. 2008. The role of tree nuts and peanuts in the prevention of coronary heart disease: multiple potential mechanisms. J Nutr 138(9):1746S-1751S.

Lam LKT, Zhang J and Hasegawa S. 1994. Citrus limonoid reduction of chemically induced tumorigenesis. Food Technol November 1994:104-108.

Lanham-New S. 2006. Fruits and vegetables: the unexpected natural answer to the question of osteoporosis prevention? Am J Clin Nutr 83:1254-1255.

Larrauri JA, Ruperez P and Galixto FS. 1997. Pineapple shell as a source of dietary fiber with associated polyphenols. J Agric Food chem. 45:4028-4031.

Larsson SC, Bergkvist L and Wolk A. 2006. Fruit and vegetable consumption and incidence of gastric cancer: a prospective study. Cancer Epidimiol Biomarkers Prev 15(10):1998-2001.

Lau F, Shukitt-Hale V and Joseph J. 2005. The beneficial effects of fruit polyphenols on brain aging. Neurobiol Aging 265:S128-S132.

Laval-Martin D, Quennement J and Moneger R. 1975. Pigment evolution in Lycopersicon esculentum fruits during growth and ripening. Phytochemistry 14:2357-2362.

Law MR and Morris JK. 1998. By how much does fruit and vegetable consumption reduce the risk of ischaemic heart disease? Eur J Clin Nutr 52:549-556. 
Le Marchand L, Yoshizawa CN, Kolonel LN, Hankin LH, Goodman MT. 1989. Intake of flavonoids and lung cancer. J Natl Cancer Inst 81:1158-1164.

Lea AGH. 1978. The phenolics of ciders: oligomeric and polymeric procyanidins. J Sci Food Agric 29:471-477.

Lea AGH. 1992. Flavor, color and stability in fruit products: the effect of polyphenols. In: Hemingway RW and Leaks PE, editors. Plant Polyphenols. New York: Plenum Press, pp. 827-847.

Lea AGH, Timberlake CF. 1974. The phenolics of cider. J Sci Food Agric 25:1537-1545.

Lee ES, Steiner M, Lin R. 1994. Thioallyl compounds: potent inhibitors of cell proliferation. Biochim Biophys Acta 1221:73-77.

Lee LM, Cook NR, Manson JE, Buring JE, Hennekens CH. 1999. $\beta$-Carotene supplementation and incidence of cancer and cardiovascular disease: the Women's Health Study. J Natl Cancer Inst 91:2102-2106.

Lee KW, Kim WJ, Kim DO, Lee HJ, Lee CY. 2003. Major phenolics in apples and their contribution to the total antioxidant capacity. J Agric Food Chem 51:6516-6520.

Lee Y, Howard LR and Villalon B. 1995. Flavonoids and antioxidant activity of fresh pepper (Capsicum aппиит) cultivars. J Food Sci 60:473-476.

Lentheric I, Pinto E, Vendrell M and Larrigaudiere C. 1999. Harvest date affects the antioxidative system in pear fruits. J Hort Sci Technol 74(6):791-795.

Leontowicz M, Gorinstein S, Leontowicz H, Krzeminski R, Lojek A, Katrich E, Ciz M, Martin-Bellozo O, Soliva-Fortuny R, Haruenkit R and Trakhtenberg S. 2003. Apple and pear peel and pulp and their influence on plasma lipids and antioxidant potentials in rats fed cholesterol-containing diets. J Agric Food Chem. 51:5780-5785.

Lewis D, Antoniak M, Venn A, Davies L, Goodwin A, Salfield N, Britton J and Fogarty A. 2005. Secondhand smoke, dietary food intake, road traffic exposures, and the prevalence of asthma: a cross-sectional study in young children. Am J Epidemiol 161:406-411.

Li S, Pan M-H, Lo C-Y, Tan D, Wang Y, Shahidi F and Ho C-T. 2009. Chemistry and health effects of polymethoxyflavones and hydroxylated polymethoxyflavones. J Funct Foods 1:2-12.

Lin P-H, Ginty F, Appel L, Aickin M, Bohannon A, Garnero P, Barcaly D and Svetkey L. 2003. The DASH diet and sodium reduction improve markers of bone turnover and calcium metabolism in adults. J Nutrition 133:3130-3136.

Lin XY, Liu JZ and Milner JA. 1994. Dietary garlic suppresses DNA adducts caused by $N$-nitroso compounds. Carcinogenesis 15:349-352.

Linseisen J, Rohrmann S, Miller AB, Bueno-de-Mesquita HB, Büchner FL, Vineis P, Agudo A, Gram IT, Janson L, Krogh V, Overvad K, Rasmuson T, Schulz M, Pischon T, Kaaks R, Nieters A, Allen NE, Key TJ, Bingham S, Khaw KT, Amiano P, Barricarte A, Martinez C, Navarro C, Quirós R, Clavel-Chapelon F, Boutron-Ruault MC, Touvier M, Peeters PH, Berglund G, Hallmans G, Lund E, Palli D, Panico S, Tumino R, Tjønneland A, Olsen A, Trichopoulou A, Trichopoulos D, Autier P, Boffetta P, Slimani N and Riboli E. 2007. Fruit and vegetable consumption and lung cancer risk: updated information from the European Prospective Investigation into Cancer and Nutrition (EPIC). Intl J Cancer 121(5):1103-1114.

Liu RH. 2004. Potential synergy of phytochemicals in cancer prevention: mechanism of action. J Nutr 134:3479S-3485S.

Liu RH, Liu J and Chen B. 2005. Apples prevent mammary tumors in rats. J Agric Food Chem 53:2341-2343.

Long M, Millar DJ, Kimura Y, Donovan G, Rees J, Fraser PD, Bramley PM and Bolwell GP. 2006. Metabolite profiling of carotenoid and phenolic pathways in mutant and transgenic lines of tomato: identification of a high antioxidant fruit line. Phytochemistry 67:1750-1757.

Lu SH, Camus AM, Tomatis L and Bartsch H. 1981. Mutagenicity of extracts of pickled vegetables collected in Linhsien County, a high-incidence area for esophageal cancer in Northern China. J Natl Cancer Inst 66(1):33-36.

AmMa J, Yang H, Basile MJ and Kennelly EJ. 2004. Analysis of polyphenolic antioxidants from the fruits of three Pouteria species by selected ion monitoring liquid chromatography/mass spectrometry. J Agric Food Chem 52:5873-5878.

Macdonald H, New S, Fraser W, Campbell M and Reid D. 2005. Low dietary potassium intakes and high dietary estimates of net endogenous acid production are associated with low bone mineral density in premenopausal women and increased markers of bone resorption in postmenopausal women. Am J Clin Nutr 81:923-933.

Macheix JJ, Fleuriet A and Billot J. 1990. Fruit Phenolics. Boca Raton, FL: CRC Press. 
Mahattanatawe K, Manthey JA, Luzio G, Talcott ST, Goodner K and Baldwin EA. 2006. Total antioxidant activity and fiber content of select Florida-grown tropical fruits. J Agric Food Chem 54:7355-7363.

Markus F, Daood HG, Kapitany J and Biacs PA. 1999. Changes in the carotenoid and antioxidant content of spice red pepper (paprika) as a function of ripening and some technological factors. J Agric Food Chem 47:100-107.

Mazliak P. 1971. Avocado lipid constituents. Fruits 26:615-623.

Mazza G. 1998. Functional Foods. Pennsylvania: Technomic.

Mayr U, Treutter D, Santos-Buelga C, Bauer H and Fuecht W. 1995. Developmental changes in the phenol concentrations of 'Golden Delicious' Apple fruits and leaves. Phytochemistry 38:115.

McDannell R and McLean AEM. 1988. Chemical and biological properties of indole glucosinolates (glucobrassicins): a review. Food Chem Toxicol 26:59-70.

Medellin MLC, Salvidar SOS and De la Garza JV. 1998. Effect of raw and cooked nopal (Opuntia ficusindica) ingestion on growth and total cholesterol, lipoproteins and blood glucose in rats. Arch Latinoamer Nutr 48:316-323.

Mejia LA, Hudson E, Gonzalez E and Vazquez F. 1988. Carotenoid content and vitamin A activity of some common cultivars of Mexican peppers (Capsicum апnиит) as determined by HPLC. J Food Sci 53:1448-1451.

Mei X, Lin X, Liu JZ, Lin XY, Song PJ, Hu JF and Liang XJ. 1989. The blocking effect of garlic on the formation of $N$-nitrosoproline in humans. Acta Nutrimenta Sinica 11:141-146.

Mei X, Wang ML, Xu HX, Pan XY, Gao CY, Han N and Fu MY. 1982. Garlic and gastric cancer. I. The influence of garlic on the level of nitrate and nitrite in gastric juice. Acta Nutrimenta Sinica 4:53-56.

Mercadante AZ, Rodriguez-Amaya DB and Britton G. 1997. HPLC and mass spectrometric analysis of carotenoids from mango. J Agric Food Chem 45:120-123.

Mertens-Talcott SU, Bomser JA, Romero C, Talcott ST and Percival SS. 2005. Ellagic acid potentiates the effect of quercetin on p21waf1/cip1, p53, and MAP-kinases without affecting intracellular generation of reactive oxygen species in vitro. J Nutr 135:609-614.

Meyer BN and McLaughlin JL. 1981. Economic uses of Opuntia. Cactus Succulent J 53:107-112.

Meyers KJ, Watkins CB, Pritts MP and Liu RH. 2003. Antioxidant and antiproliferative activities of strawberries. J Agric Food Chem 51:6887-6892.

Michels KB, Giovannucci E, Joshipura KJ, Rosner BA, Stampfer MJ, Fuchs CS, Codlitz GA, Speizer FE and Willett W. 2000. Prospective study of and incidence of colon and rectal cancers. J Natl Cancer Inst 92:1749-1752.

Middleton E Jr. and Kandaswami C. 1994. Potential health-promoting properties of citrus flavonoids. Food Technol November 1994:115-119.

Miean KH and Mohamed S. 2001. Flavonoid (myricetin, quercetin, kaempferol, luteolin, and apigenin) content of edible tropical plants. J Agric Food Chem 49:3106-3112.

Millburry P, Chen C-Y, Kwak H-K and Blumberg J. 2002. Almond skins polyphenolics act synergistically with alpha-tocopherol to increase the resistance of low-density lipoproteins to oxidation. Free Rad Res 36(1 suppl):78-80.

Miller NJ and Rice-Evans CA. 1997. The relative contributions of ascorbic acid and phenolic antioxidants to the total antioxidant activity of orange and apple fruit juices and blackcurrant drinks. Food Chem 60:331-337.

Minguez-Mosquera MI and Hornero-Mendez D. 1994. Comparative study of the effect of paprika processing on the carotenoids in peppers (Capsicum апnиum) of the Bola and Agridulce varieties. J Agric Food Chem 42:1555-1560.

Moeller S, Taylor A, Tucker K, McCullogh M, Chylack L, Hankinson S, Willet W and Jacques P. 2004. Overall adherence to the Dietary Guidelines for Americans is associated with reduced prevalence of early age-related nuclear lens opacities in women. J Nutr 134:1812-1819.

Mori K, Toyomasu T, Nanba H and Kuroda H. 1987. Antitumor action and fruit bodies of edible mushrooms orally administered to mice. Mush J Tropics 7:121-126.

Muller H. 1997. Determination of the carotenoid content in selected vegetables and fruits by HPLC and photodiode array detection. Z Lebensm Unters Forsch 204:88-94.

Nagura J, Iso H, Watanabe Y, Maruyama K, Date C, Toyoshima H, Yamamoto A, Kikuchi S, Koizumi A, Kondo T, Wada Y, Inaba Y and Tamakoshi A. 2009. Fruit, vegetable and bean intake and mortality from cardiovascular disease among Japanese men and women: the JACC Study. Br J Nutr 13:1-8. 
Nakamura K, Nagata C, Oba S, Takatsuka N and Shimizu H. 2008. Fruit and vegetable intake and mortality from cardiovascular disease are inversely associated in Japanese women but not in men. J Nutr 138(6):1129-1134.

Naska A, Vasdekis V, Trichopoulou A, Friel S, Leonhauser I and Moreira G. 2000. Fruits and vegetable availability among ten European countries: how does it compare with the "five-a-day" recommendation? Brit J Nutr 84:549-556.

Ness A, Egger M and Powles J. 1999. Fruit and vegetable and ischaemic heart disease: systematic review or misleading meta-analysis? Eur J Clin Nutr 53:900-902.

Ness A and Powles JW. 1997. Fruit and vegetables, and cardiovascular disease: a review. Int J Epidemiol 26:1-13.

Nettleton JA, Steffen LM, Ni H, Liu K and Jacobs DR Jr. 2008. Dietary patterns and risk of incident type 2 diabetes in the Multi-Ethnic Study of Atherosclerosis (MESA). Diabetes Care 31(9):1777-1782.

Okabo H, Sasaki S, Horiguchi H, Oguma E, Miyamoto K, Hosoi Y, Kim M- and Kayama F. 2006. Dietary patterns associated with bone mineral density in premenopausal Japanese farmwomen. Am J Nutr 83(5):1185-1192.

Oleszek W, Lee CY, Jaworzki AW and Price KR. Identification of some phenolic compounds in apples. J Agric Food Chem 36:430-436.

Oloyede OI. 2005. Chemical profile of unripe pulp of Carica papaya. Pakistan J Nutr 4:379-381.

Olmedilla B, Granado F, Southon S, Wright AJA, Blanco I, Gil-Martinez E, Berg H, Corridan B, Roussel AM, Chopra M and Thurnham DI. 2001. Serum concentrations of carotenoids and vitamins A, E, and C in control subjects from five European countries. British J Nutr 85(2):227-238.

Omenn GS, Goodman GE, Thornkist MD, Balmes J, Cullen MR, Glass A, Keogh JP, Meyskens FL, Valanis B, Williams JH, Barnhart S, Cherniack MG, Brodkin CA and Hammar S. 1996. Risk factors for lung cancer and for intervention effects in CARET, the Beta-Carotene and Retinol Efficacy Trial. J Nat Cancer Inst 88:1550-1559.

Ornelas-Paz JJ, Yahia EM and Gardea A. 2007. Identification and quantification of xanthophyll esters, carotenes and tocopherols in the fruit of seven Mexican mango cultivars by liquid chromatography$\mathrm{APcI}^{+}$-time of flight mass spectrometry. J Agric Food Chem 55:6628-6635.

Ornelas-Paz JJ, Yahia EM and Gardea-Bejar A. 2008. Relationship between fruit external and internal color and carotonoids content in Manila and Ataulfo mangoes determined by liquid chromatography-APcI ${ }^{+}$ time of flight mass spectrometry. Postharv Biol Technol 50:145-152.

Osuna-Garcia JA, Wall MM and Waddell CA. 1998. Endogenous levels of tocopherols and ascorbic acid during fruit ripening of New Mexican-type chile (Capsicum annuиm). J Agric Food Chem 46:5093-5096.

Park EH, Kahng JH and Paek EA. 1998. Studies on the pharmacological actions of cactus: identification of its anti-inflammatory effect. Arch Pharmaceutical Res 21(1):30-34, 63.

Patel B, Welch A, Bingham S, Luben R, Day N, Khaw K, Lomas D and Wareham N. 2006. Dietary antioxidants and asthma in adults. Thorax 61:388-393.

Pattison D, Symmons D, Lunt M, Welch A, Birngham S, Day N and Silman A. 2005. Dietary $\beta$ cryptoxanthin and inflammatory polyarthritis: results from population-based prospective study. Am J Clin Nutr 82:451-455.

Pattison D, Symmons D and Young A. 2004b. Does diet have a role in the aetiology of rheumatoid arthritis? Proc Nutr Soc 63:137-143.

Pendlington S, Dupont MS and Trussel FJ. 1965. The carotenoid composition of Solanum tuberosum. Biochem J 94:25-26.

Percival SS, Talcott ST, Chin ST, Mallak AC, Lound-Singleton A and Pettit-Moore J. 2006. Neoplastic transformation of BALB/3T3 cells and cell cycle of HL-60 cells are inhibited by mango (Mangifera indica L.) juice and mango juice extract. J Nutr 136:1300-1304.

Pinent M, Blay M, Bladé MC, Salvadó MJ, Arola L and Ardévol A. 2004. Grape seed-derived procyanidins have an antihyperglycemic effect in streptozotocin-induced diabetic rats and insulinomimetic activity in insulin-sensitive cell lines Endocrinology 145(11):4985-4990.

Plumb GW, Lamer N, Chambers SJ, Wanigatunga S, Heany RK, Plumb JA, Aruoma OI, Halliwell B, Miller $\mathrm{NJ}$ and Williamson G. 1996a. Are whole extracts and purified glucosinolates from cruciferous vegetables antioxidants? Free Rad Res 25:75-86.

Plumb GW, Chambers SJ, Lambert N, Bartolome B, Heaney RK, Wangatunga S, Aruoma OI, Halliwell B and Williamson G. 1996b. Antioxidant actions of fruit, herb and spice extracts. J Food Lipids 3:171-178. 
Plumb GW, Chambers SJ, Lambert N, Wanigatunga S and Williamson G. 1997a. Influence of fruit and vegetable extracts on lipid peroxidation in microsomes containing specific cytochrome P450s. Food Chem 60:161-164.

Plumb GW, Price KR, Rhodes MJC and Williamson G. 1997b. Antioxidant properties of the major polyphenolic compounds in broccoli. Free Rad Res 27:429-435.

Prior RL, Cao G. 2000. Antioxidant phytochemicals in fruits and vegetables: diet and health implications. Hort Sci 35:588-592.

Prior RL, Cao G, Martin A, Sofic E, McEwen J, OBrien C, Lischner N, Ehlenfeldt M, Kalt W, Krewer G and Mainland CM. 1998. Antioxidant capacity as influenced by total phenolic and anthocyanidin content, maturity, and variety of Vaccinium species. J Agric Food chem. 46:2686-2693.

Pryne C, Mishra G, O'Connell MA, Muniz G, Laskey MA, Yan L, Prentice A and Ginty F. 2006. Fruit and vegetable intakes and bone mineral status: a cross-sectional study in 5 age and sex cohorts. Am J Clin Nutr 83:1420-1428.

Radhika G, Sudha V, Mohan Sathya R, Ganesan A and Mohan V. 2008. Association of fruit and vegetable intake with cardiovascular risk factors in urban south Indians. Br J Nutr 99(2):398-405.

Raicht RF, Cohen BI, Fazzini EP, Sarwal AN and Takahashi M. 1980. Protective effect of plant sterols against chemically induced colon tumors in rats. Cancer Res 40:403-405.

Ramarathnam N, Ochi H, Takeuchi M. 1997. Antioxidative defense system in vegetable extracts. In Shahidi F, editor. Natural Antioxidants. Chemistry, Health Effects, and Applications. Champaign, IL: AOCS Press, pp. $76-87$.

Rechkemmer G. 2001. Funktionelle Lebensmittel-Zukunft de Ernahrung oder Marketing-Strategie. Forschungereport Sonderheft 1:12-15.

Reddy BS, Mori H and Nicolais M. 1981. Effect of dietary wheat bran and dehydrated citrus fiber on azoxymethane-induced intestinal carcinogenesis in Fischer 344 rats. J Natl Cancer Inst 66:553-557.

Ren Y, Waldron KW, Pacy JE and Ellis PR. 2001. Chemical and histochemical characterization of cell wall polysaccharides in almond seeds in relation to lipid bioavailability. In: Pfannhauser W, Fenwick GR and Khokhar S, editors. Biologically Active Phytochemicals in Foods. Cambridge, UK: Royal Soc Chem, pp. $448-452$.

Retelny VS, Neuendorf A and Roth JL. 2008. Nutrition protocols for the prevention of cardiovascular disease. Nutr Clin Pract 23(5):468-476.

Ribaya-Mercado JD, Garmyn M, Gilchrest BA and Russel RM. 1995. Skin lycopene is destroyed preferentially over $\beta$-carotene during ultraviolet irradiation in humans. J Nutr 125:1854-1859.

Ricardo-da-Silva JM, Rosec JP, Bourzeix M and Heredia N. 1990. Separation and quantitative determination of grape and wine procyanidins by HPLC. J Sci Food Agric 53:85-92.

Rissanen TH, Voutilainen S, Virtanen JK, Venho B, Vanharanta M, Mursu J and Salonen JT. 2003. Low intake of fruit, berries and vegetables is associated with excess mortality in men: the Kuopio Ischaemic Heart Disease Risk Factor (KIHD) Study. J Nutr 133:199-204.

Rivera-Pastarna D, Yahia EM and Gonzalez-Aguilar G. 2009. Identification and quantification of carotenoids and phenolic compounds in papaya using mass spectroscopy. In preparation.

Robards K, Prenzler PD, Tucker G, Swatsitang P and Glover W. 1999. Phenolic compounds and their role in oxidative processes in fruits. Food Chem 66:401-436.

Rodriguez de Sotillo D, Hadley M, Holm ET. 1994. Phenolic in aqueous potato peel extract: extraction, identification and degradation. J Food Sci 59:649-651.

Rodriguez-Saona LE, Giusti MW and Wrolstad RE. 1998. Anthocyanin pigment composition of red-fleshed potatoes. J Food Sci 63:458-465.

Romieu I, Varraso R, Avenel V, Leynaert B, Kauffman F and Clavel-Chapelon F. 2006. Fruit and vegetable intakes and asthma in the E3N study. Thorax 61:209-215.

Rouseff RL and Nagy S. 1994. Health and nutritional benefits of citrus fruit components. Food Technol November 1994:125-130

Rungapamestry V, Duncan AJ, Fuller Z and Ratcliffe B. 2007. Effect of cooking Brassica vegetables on the subsequent hydrolysis and metabolic fate of glucosinolates. Proc Nutr Soc 66(1):69-81.

Sang S, Kikuzaki H, Lapsley K, Rosen RT, Nakatani N and Ho CT. 2002. Sphingolipid and other constituents from almond nuts (Prunus amygdalus Batsch). J Agric Food chem. 50:4709-4712.

Santos CA and Simon PW. 2002. QTL analyses reveal clustered loci for accumulation of major provitamin A carotenes and lycopene in carrot roots. Mol Genet Genomics 268:122-129. 
Sarkar D, Sharma A and Talukder G. 1994. Chlorophyll and chlorophyllin as modifiers of genotoxic effects. Mutat Res 318(3):239-247.

Sautter C, Poletti S, Zhang P and Gruissem W. 2006. Biofortification of essential nutritional compounds and trace elements in rice and cassava. Proc Nutr Soc 65:153-159.

Schauer N, Semel Y, Roessner U, Gur A, Balbo I, Carrari F, Pleban T, Perez-Melis A, Bruedigam C, Kopka J, Willmitzer L, Zamir D and Fernie AR. 2006. Comprehensive metabolic profiling and phenotyping of interspecific introgression lines for tomato improvement. Nat Biotechnol 24:447-454.

Schijlen E, Ric de Vos CH, Jonker H, van den Broeck H, Molthoff J, van Tunen A, Martens S and Bovy A. 2006. Pathway engineering for healthy phytochemicals leading to the production of novel flavonoids in tomato fruit. Plant Biotechnol J 4(4):433-444.

Schreiner M. 2005. Vegetable crop management strategies to increase the quantity of phytochemicals. Eur J Nutr 44:85-94.

Serrano M, Guillen F, Martinez-Romero D, Castillo S and Valero D. 2005. Chemical constituents and antioxidant activity of sweet cherry at different ripening stages. J Agric Food Chem 53:2741-2745.

Shannon J, Cook LS and Stanford JL. 2003. Dietary intake and risk of postmenopausal breast cancer (United States). Cancer Causes Control 14:19-27.

Shi J and Le Maguer M. 2000. Lycopene in tomatoes: chemical and physical properties affected by food processing. Crit Rev Food Sci Nutr 40(1):1-42.

Shukitt-Hale B, Carey A, Simon L, Mark D and Joseph J. 2006. Effect of Concord grape juice on cognitive motor deficits in aging. Nutrition 22:295-302.

Siddapa GS and Bhatia BS. 1954. The identification of sugars in fruits by paper chromatography. Indian J Hort 11:104.

Silaste M, Rantala M, Alftham G, Aro A and Kessaniemi Y. 2003. Plasma homocysteine concentration is decreased by dietary intervention. Br J Nutr 89:295-301.

Simmone AH, Simmone EH, Eitenmiller RR, Mills HA and Green NR. 1997. Ascorbic acid and provitamin A contents in some unusually colored bell peppers. J Food Compos Anal 10:299-311.

Sisini A. 1969. Sulla glucose-6-fosfato isomerasi in Opuntia ficus-indica. Boll Soc Ital Biol Sper 45:794796.

Slade AJ and Knauf VC. 2005. TILLING moves beyond functional genomics into crop improvement. Transgenic Res 14:109-115.

Smith-Warner SA, Spiegelman D, Shiaw-Shyuan Y, Adami HO, Beeson WL, Brandt PA, Folsom AR, Fraser GE, Freudenheim JL, Goldbohm RA, Graham S, Miller AB, Potter JD, Rohan TE, Speizer FE, Toniolo P, Willet WC, Wolk A and Zeleniuch-Jacquotte A, Hunter DJ. 2001. Intake of fruits and vegetables and risk of breast cancer. A pooled analysis of cohort studies. J Am Med Assoc 285(6):769-776.

Somers TC and Ziemelis G. 1985. Spectral evaluation of total phenolic components in Vitis vinifera: grapes and wines. J Sci Food Agric 36:1275-1284.

Sondheimer E and Karash CB. 1956. The major anthocyanin pigments of the wild strawberry (Fragaria vesca). Nature 178:648-649.

Spanos GA, Worlstad RE and Heatherbell DA. 1990. Influence of processing and storage on the phenolic composition of apple juice. J Agric Food Chem 38:1572-1579.

Stahl W and Sies H. 1996. Lycopene: a biologically important carotenoid for humans? Arch Biochem Biophys 336:1-9.

Stark MJ, Burke YD, McKinzie JH, Ayoubi AS and Crowell PL. 1995. Chemotherapy of pancreatic cancer with the monoterpene perillyl alcohol. Cancer Lett 96:15-21.

Stavric B. 1994. Role of chemopreventers in human diet. Clin Biochem 27(5):319-332.

Steinmetz KA, Kushi LH, Bostick RM, Folsom AR and Potter JD. 1994. Vegetables, fruit and colon cancer in the Iowa Women's Health Study. Am J Epidemiol 139:1-15.

Steinmetz K and Potter J. 1991. Vegetables, fruit, and cancer. Cancer Causes Control 2:325-442.

Steinmetz KA and Potter JD. 1996. Vegetables, fruit and cancer prevention: a review. J Am Diet Assoc 96:1027-1039.

Steinmetz KA, Potter JD and Folsom AR. 1993. Vegetables, fruit, and lung cancer in the Iowa Women's Health Study. Cancer Res 53:536-543.

Stintzing FC, Schieber A and Carle R. 2002. Identification of betalains from yellowbeet (beta vulgaris L.) and cactus pear (Opuntia ficus-indica L. Mill.) by high performance liquid chromatography-electrospray ionization mass spectroscopy. J Agric Food Chem 50:2302-2307. 
Stoewsand GS. 1995. Bioactive organosulfur phytochemicals in Brassica oleracea vegetables. A review. Food Chem Toxicol 33(6):537-543.

Stram DO, Hankin JH, Wilkens LR, Park S, Henderson BE, Nomura AM, Pike MC and Kolonel LN. 2006. Prostate cancer incidence and intake of fruits, vegetables and related micronutrients: the multiethnic cohort study (United States). Cancer Causes Control 17(9):1193-1207.

Sugie S, Okumura A, Tanaka T and Mori H. 1993. Inhibitory effects of benzylisothiocyanate and benzylthiocyanate on diethylnitrosamine-induced hepatocarcinogenesis in rats. Jpn J Cancer Res 84:865870.

Sun J, Chu Y-F, Wu X and Lui RH. 2002. Antioxidant and antiproliferative activities of common fruits. J Agric Food Chem 50:6910-6916.

Suzuki S, Takada T, Sugawara Y, Muto T and Kominami R. 1991. Quercetin induces recombinational mutations in cultured cells as detected by DNA fingerprinting. Jpn J Cancer Res 82(10):1061-1064.

Svendsen M, Blomhoff R, Holme I, Tonstad S. 2007. The effect of an increased intake of vegetables and fruit on weight loss, blood pressure and antioxidant defense in subjects with sleep related breathing disorders. Eur J Clin Nutr 61(11):1301-1311.

Syngletary KW, Jackson SJ, Milner JA. 2005. Non-nutritive components in foods as modifiers of the cancer process. In: Bendich A and Deckelbaum RJ, editors. Preventive Nutrition: the Comprehensive Guide for Health Professionals, 3rd ed. Totowa, NJ: Humana Press.

Tabak C, Wijga A, de Meer G, Janssen N, Brunekreef B and Smith H. 2006. Diet and asthma in Dutch school children (ISAAC-2). Thorax 61(12):1048-1053.

Takahashi Y, Nagao M, Fujino T, Yamaizumi Z and Sugimura T. 1979. Mutagens in Japanese pickle identified as flavonoids. Mut Res 68:117-123.

Tanaka T, Mori Y, Morishita Y, Hara A, Ohno T, Kojinna T and Mori H. 1990. Inhibitory effect of sinigrin and indole-3-carbinol on diethylenitrosamine-induced hepatocarcinogenesis in male AC/N rats. Carcinogenesis 11:1403-1406.

Tango JS, Dacosta ST, Antunes AJ and Figueriedo IB. 1972. Composition of fruit oil of different varieties of avocados grown in Sao Paulo. Fruits 27:143-146.

Terry P, Giovannucci E, Michels KB, Bergkvist L, Hansen H, Holmberg L and Wolk A. 2001. Fruit, vegetables, dietary fiber, and risk of colorectal cancer. J Natl Cancer Inst 93(7):525-533.

Tesoriere L, Butera D, Pintaudi AM, Allegra M and Livrea MA. 2004. Supplementation with cactus pear (Opuntia ficus-indica) fruit decreases oxidative stress in healthy humans: a comparative study with vitamin C. Am J Clin Nutr 80:391-395.

Thomas P. 1975. Effect of postharvest temperatures on quality, carotenoids and ascorbic acid contents in Alphonso mangos on ripening. J Food Sci 40:704-706.

Thompson RS, Jaques D, Haslam E and Tanner RJN. 1972. Plant proanthocyanidins. Part 1. J Chem Soc Perkin Trans 1:1837-1841.

Tsugani S, Tsuda M, Gey F and Watanabe S. 1992. Cross-sectional study with multiple measurements of biological markers for assessing stomach cancer risks at the population level. Environ Health Perspect 98:207-210.

Turnball WH, Walton J and Leeds AR. 1993. Acute effects of mycoprotein on subsequent energy intake and appetite variables. Am J Clin Nutr 58(4):507-512.

Tussedre PL, Frankel EN, Waterhouse AL, Peleg H and German JB. 1996. Inhibition of in vitro human LDL oxidation by phenolic antioxidants from grapes and wines. J Sci Food Agric 70:55-61.

Tylavsky F, Holliday K, Danish R, Womack C, Norwood J and Carbone L. 2004. Fruit and vegetable intakes are an independent predictor of bone size in early pubertal children. Am J Clin Nutr 79:311-317.

USDA. 1991. Composition of Foods: Fruits and Fruit Products-Raw, Processed, Prepared. US Dept Agr Handb 8-9, 283 pp.

USDA Economic Research Service. 2002. Food consumption per capita. www.ers.usda.gov/data/ foodconsumption/

VanEenwyk J, Davis FG and Bowen PE. 1991. Dietary and serum carotenoids and cervical intraepithelial neoplasia. Int J Cancer 48:34-38.

Van Gils C, Peeters PH, Bueno-de-Mesquita HB, Boshuizen HC, Lahmann PH, Clavel-Chapelon F, Thiebaut A, Kesse E, Sieri S, Palli D, Tumino R, Panico S, Vineis P, Gonzalez CA, Ardanaz E, Sanchez MJ, Amiano P, Navarro C, Quiros JR, Key TJ, Allen N, Khaw KT, Bingham SA, Psaltopoulou T, Koliva M, Trichopoulou A, Nagel G, Linseisen J, Boeing H, Berglund G, Wirfalt E, Hallmans G, Lenner P, Overvad 


\section{Fruit and Vegetable Phytochemicals}

K, Tjonneland A, Olsen A, Lund E, Engeset D, Alsaker E, Norat TA, Kaaks R, Slimani N and Riboli E. 2005. Consumption of vegetables and fruit and risk of breast cancer. JAMA 293:183-193.

Vatanparast H, Baxter-Jones A, Faulkner R, Baile D and Whiting S. 2005. Positive effects of vegetable and fruits consumption and calcium intake on bone mineral accrual in boys during growth from childhood to adolescence: the University of Saskatchewan Pediatric Bone Mineral Accrual Study. Am J Clin Nutr 82:700-706.

Velioglu YS, Mazza G, Gao L and Oomah DB. 1998. Antioxidant activity and total phenolics in selected fruits, vegetables, and grain products. J Agric Food Chem 46:4113-4117.

Verhagen H, Poulsen HE, Loft S, Van-Poppel G, Willems MI and Van-Bladeren PJ. 1995. Reduction of oxidative DNA-damage in humans by Brussels sprouts. Carcinogenesis 16(4):969-970.

Villegas R, Shu XO, Gao YT, Yang G, Elasy T, Li H and Zheng W. 2008. Vegetable but not fruit consumption reduces the risk of type 2 diabetes in Chinese women. J Nutr 138(3):574-580.

Vinson JA, Hao Y, Su X and Zubik L. 1998. Phenol antioxidant quantity and quality in foods: vegetables. J Agric Food Chem 46:3630-3634.

Vioque J, Weinbrenner T, Castelló A, Asensio L and Garcia de la Hera M. 2008. Intake of fruits and vegetables in relation to 10-year weight gain among Spanish adults. Obesity (Silver Spring) 16(3):664-670.

Voorips LE, Goldbohm RA, van Poppel G, Sturmans F, Hermus RJ and van den Brandt PA. 2000. Vegetable and fruit consumption and risk of colon and rectal cancer in a prospective cohort study. Am J Epidemiol 152:1081-1092.

Walda I, Tabak C, Smith H, Rasanen L, Fidanza F, Menotti A, Nissinen A, Feskens E and Kromhout D. 2002. Diet and 20-year chronic obstructive pulmonary disease mortality in middle-aged men from three European countries. Eur J Clin Nutr 2002:638-643.

Wang H, Cao G and Prior RL. 1996. Total antioxidant capacity of fruits. J Agric Food Chem 44:701705.

Wang SY, Feng R, Lu Y, Bowman L and Ding M. 2005. Inhibitory effect on activator protein-1, nuclear factor-kappab, and cell transformation by extracts of strawberries (fragaria $\times$ ananassa duch.). J Agric Food Chem 53:4187-4193.

Wang SY and Jiao HJ. 2000. Scavenging capacity of berry crops on superoxide radicals, hydrogen peroxide, hydroxyl radicals, and singlet oxygen. J Agric Food Chem 48:5677-5684.

Wang SY and Lin HS. 2000. Antioxidant activity in fruit and leaves of blackberry, raspberry, and strawberry is affected by cultivar and maturity. J Agric Food Chem 48:140-146.

Wargovich MJ. 2000. Anticancer properties of fruits and vegetables. HortSci 35(4):573-575.

Watson L, Margetts B, Howarth P, Dorwarth M, Thompson R and Little P. 2002. The association between diet and chronic obstructive pulmonary disease in subjects selected from general practice. Eur Respir $\mathbf{J}$ 20:313-318.

Wattenberg LW. 1975. Effects of dietary constituents on the metabolism of chemical carcinogens. Cancer Res 35(11):3326-3331.

Wattenberg LW and Coccia JB. 1991. Inhibition of 4-(methylnitrosamino)-1-(3-pyridyl)butanone carcinogenesis in mice by D-limonene and citrus fruit oil. Carcinogenesis 12:115-117.

Wattenberg LW and Loub WD. 1978. Inhibition of polycyclic aromatic hydrocarbon-induced neoplasia by naturally occurring indoles. Cancer Res 38:1410-1413.

Whanger PD, Ip C, Polan CE, Uden PC and Welbaum G. 2000. Tumorigenesis, metabolism, speciation, bioavailability, and tissue deposition of selenium in selenium-enriched ramps (Allium tricoccum). J Agric Food Chem 48(11):5723-5730.

Whiting GC and Coggins RA. 1975a. 4-p-Coumaroyl quinic acid in apple fruits. Phytochemistry 14:593-597.

Whiting GC and Coggins RA. 1975b. Estimation of the monomeric phenolics of ciders. J Sci Food Agric 26:1833-1839.

William R, Spencer J and Rice-Evans C. 2004. Flavonoids: antioxidants or signaling molecule? Free Radic Biol Med 36:838-849.

Wolfe K, Wu X and Liu RH. 2003. Antioxidant activity of apple peels. J Agric Food Chem 51:609-614.

World Cancer Research Fund Food. 1997. Nutrition and the Prevention of Cancer: A Global Perspective. Washington DC: American Institute for Cancer Research.

Wright ME, Park Y, Subar AF, Freedman ND, Albanes D, Hollenbeck A, Leitzmann MF and Schatzkin A. 2008. Intakes of fruit, vegetables, and specific botanical groups in relation to lung cancer risk in the NIH-AARP Diet and Health Study. Am J Epidemiol 168(9):1024-1034. 
Yahia EM. 2006. Handling tropical fruits. In Scientists Speak. Alexandria, VA: World Foods Logistics Organization, pp. 5-9.

Yahia EM. 2009a. Prickly pear. Chapter 13. In: Rees D, Farrell G, Orchard JE, editors. Crop Postharvest: Science and Technology, Volume 3. Oxford: Wiley-Blackwell. In press.

Yahia EM. 2009b. Avocado. Chapter 8. In: Rees D, Farrell G, Orchard JE, editors. Crop Postharvest: Science and Technology, Volume 3. Oxford: Wiley-Blackwell. In press.

Yahia EM and Brecht JK. 2009. Tomato. Chapter 2. In: Rees D, Farrell G, Orchard JE, editors. Crop Postharvest: Science and Technology, Volume 3. Oxford: Wiley-Blackwell. In press.

Yahia EM, Contreras M and Gonzalez G. 2001b. Ascorbic acid content in relation to ascorbic acid oxidase activity and polyamine content in tomato and bell pepper fruits during development, maturation and senescence. Lebensm Wiss u-Technol 34:452-457.

Yahia EM, Ornelas-Paz JJ and Gardea A. 2006. Extraction, separation and partial identification of Ataulfo mango fruit carotenoids. Acta Hortic 712:333-338.

Yahia EM, Soto G, Puga V and Steta M. 2001a. Hot air treatment effect on the postharvest quality and ascorbic acid content in tomato fruit. In: Artes F, Gil MI and Conesa MA, editors. Improving Postharvest Technologies of Fruits, Vegetables and Ornamentals, Volume 2. Paris: International Institute of Refrigeration, pp. 550-556.

Yang J, Meyers KJ, van der Heide J and Liu RH. 2004. Varietal differences in phenolic content and antioxidant and antiproliferative activities of onions. J Agric Food Chem 52:6787-6793.

Ye H, Lozada M and West B. 2005. Diverticulosis coli: Update on a "Western" disease. Adv Anat Pathol 12:74-80.

Ye X, Al-Babili S, Kloti A, Zhang J, Lucca P, Beyer P, Potrykus I. 2000. Engineering the provitamin A (beta-carotene) biosynthetic pathway into (carotenoid-free) rice endosperm. Science 287:303-305.

You WC, Blot WJ, Chang YS, Ershow AG, Yang ZT, An Q, Henderson B, Xu WG, Fraumeni JF and Wang TG. 1989. Allium vegetables and reduced risk of stomach cancer. J Natl Cancer Inst 81:162-164.

Zhang Y and Talalay P. 1994. Anticarinogenic activities of organic isothiocyanate: chemistry and mechanisms. Cancer Res 54:1976s-1981s.

Zhang LX, Cooney RV and Bertram JS. 1992. Carotenoids up-regulate connexin-43 gene expression independent of their provitamin-A or antioxidant properties. Cancer Res 52:5707-5712.

Ziegler RG, Blot WJ, Hoover R, Blattner WA and Fraumeni JF Jr. 1981. Protocol for a study of nutritional factors and the low risk of colon cancer in Southern retirement areas. Cancer Res 41:3724-3726. 
c01 BLBS045-DelaRosa September 30, 2009 15:46 Char Count= 